Working Paper/Document de travail 2013-52

\title{
Do Oil Price Increases Cause Higher Food Prices?
}

by Christiane Baumeister and Lutz Kilian 
Bank of Canada Working Paper 2013-52

December 2013

\title{
Do Oil Price Increases Cause Higher Food Prices?
}

\author{
by \\ Christiane Baumeister $^{1}$ and Lutz Kilian ${ }^{2}$ \\ 1International Economic Analysis Department \\ Bank of Canada \\ Ottawa, Ontario, Canada K1A 0 G9 \\ 2Department of Economics \\ University of Michigan \\ Ann Arbor, MI 48104 \\ Corresponding author: Ikilian@umich.edu
}

Bank of Canada working papers are theoretical or empirical works-in-progress on subjects in economics and finance. The views expressed in this paper are those of the authors.

No responsibility for them should be attributed to the Bank of Canada. 


\section{Acknowledgements}

Preliminary version of a paper prepared for the 59th Panel Meeting of Economic Policy, April 2014. We thank Soren Anderson, Michael Ehrmann, Scott Irwin, Will Martin and Aaron Smith for helpful discussions. 


\begin{abstract}
U.S. retail food price increases in recent years may seem large in nominal terms, but after adjusting for inflation have been quite modest even after the change in U.S. biofuel policies in 2006. In contrast, increases in the real prices of corn, soybeans, wheat and rice received by U.S. farmers have been more substantial and can be linked in part to increases in the real price of oil. That link, however, appears largely driven by common macroeconomic determinants of the prices of oil and agricultural commodities, rather than the pass-through from higher oil prices. We show that there is no evidence that corn ethanol mandates have created a tight link between oil and agricultural markets. Rather, increases in food commodity prices not associated with changes in global real activity appear to reflect a wide range of idiosyncratic shocks ranging from changes in biofuel policies to poor harvests. Increases in agricultural commodity prices, in turn, contribute little to U.S. retail food price increases, because of the small cost share of agricultural products in food prices. There is no evidence that oil price shocks have caused more than a negligible increase in retail food prices in recent years. Nor is there evidence for the prevailing wisdom that oil-price-driven increases in the cost of food processing, packaging, transportation and distribution are responsible for higher retail food prices. Finally, there is no evidence that oil-market-specific events or, for that matter, U.S. biofuel policies help explain the evolution of the real price of rice, which is perhaps the single most important food commodity for many developing countries.
\end{abstract}

JEL classification: Q42, Q11, Q43, E31

Bank classification: Inflation and prices; International topics

\title{
Résumé
}

Les hausses des prix des aliments au détail enregistrées aux États-Unis ces dernières années peuvent sembler importantes en termes nominaux. Toutefois, une fois rajustées de l'inflation, elles s'avèrent assez modestes, même après la modification, en 2006, des politiques américaines en matière de biocarburants. En comparaison, les augmentations des prix réels du maïs, du soja, du blé et du riz payés aux agriculteurs américains ont été plus prononcées, et peuvent être en partie liées à l'appréciation des prix réels du pétrole brut. Néanmoins, ce lien ne serait pas le fait de répercussions du renchérissement du pétrole, mais serait plutôt largement attribuable à des facteurs macroéconomiques qui influent à la fois sur les cours de l'or noir et sur les prix des produits de base agricoles. Selon les auteurs, rien ne permet d'affirmer que l'obligation d'incorporer dans l'essence de l'éthanol issu du maïs ait créé un lien étroit entre les marchés pétroliers et agricoles. Au contraire, les augmentations des prix des produits de base alimentaires qui ne sont pas associées à des variations de l’activité réelle mondiale semblent refléter un large éventail de chocs idiosyncrasiques, que ce soit la modification des politiques en matière de biocarburants ou de mauvaises récoltes. Le renchérissement des produits de base agricoles joue un rôle limité dans la hausse des prix des aliments au détail aux États-Unis, 
étant donné la faible part que représentent ces produits dans le coût des denrées alimentaires. Rien n'indique que les chocs pétroliers aient eu plus qu'un effet négligeable sur l'augmentation des prix des aliments au détail au cours des dernières années. En outre, aucun élément n'étaye l’idée répandue selon laquelle le renchérissement des aliments au détail serait attribuable à un accroissement des coûts de traitement, d'emballage, de transport et de distribution causé par la hausse des prix du pétrole. Enfin, les auteurs n’ont trouvé aucune indication que des événements touchant spécifiquement les marchés pétroliers, ou d'ailleurs les politiques américaines en matière de biocarburants, contribuent à expliquer l'évolution du prix réel du riz, sans doute le principal produit de base alimentaire dans de nombreux pays en développement.

Classification JEL : Q42, Q11, Q43, E31

Classification de la Banque : Inflation et prix; Questions internationales 


\section{Non-Technical Summary}

The persistent increase in agricultural commodity prices and food prices since 2006 has stirred a debate among policy-makers about a pending global food shortage and about inflationary pressures. This surge in food prices occurred following a similar surge in the price of crude oil, raising the suspicion that oil and food crop prices have become more closely linked in recent years. One concern is that this link may have been strengthened by the increased reliance on biofuels in industrialized economies. The goal of this paper is to investigate what the evidence is for a link from oil prices to food prices and to examine the transmission of oil price shocks to food prices both prior to and after the change in U.S. biofuel policies in 2006.

We show that there is no evidence that U.S. retail food prices closely track oil prices before and after this shift in U.S. policy. Despite considerable variation in the real price of oil, indices of real retail prices of food faced by U.S. consumers remained remarkably stable over time even after the change in U.S. biofuel policies. Instead, increases in the real prices of corn, soybeans, wheat and rice received by U.S. farmers have been more substantial and can be linked in part to increases in the real price of oil. That link, however, appears largely driven by common macroeconomic determinants of the prices of oil and agricultural commodities, rather than the pass-through from higher oil prices. Increases in agricultural commodity prices, in turn, contribute little to U.S. retail food price increases, because of the small cost share of agricultural products in food prices. 


\section{Introduction}

The persistent increase in agricultural commodity prices and food prices since 2006 has raised concerns among policy-makers about a global food shortage and about inflationary pressures. For example, the Financial Times on 23 May 2007 reported that "retail food prices are heading for their biggest annual increase in as much as 30 years, raising fears that the world faces an unprecedented period of food price inflation" (Wiggins 2007). The director of the International Food Policy Research Institute in 2008 testified before the U.S. Congress that rising prices for agricultural crops were causing food riots in many developing countries, and that, according to the Food and Agriculture Organization of the United Nations, 37 countries were now facing food crises (Rosegrant 2008). In 2011, the World Bank predicted that millions more people would be driven into poverty by higher food prices in the absence of policy changes (Inman 2011). In response to these concerns, the U.S. National Bureau of Economic Research convened a panel of academic experts in 2012 to study the recent increase in food price volatility (Chavas, Hummels and Wright 2013). Moreover, numerous government agencies pondered the causes and policy implications of price volatility in food and agricultural markets (see, e.g., 2011 Interagency Report to the G20).

There is also widespread concern that this global food crisis has an impact on food prices in industrialized economies. For example, the Chicago Tribune on 21 February 2008 reported that "increases in the price of basic commodities such as grain and milk have resulted in a tighter squeeze on American families as they face the fastest rise in food prices in nearly 20 years." Many news outlets highlighted extraordinary increases in individual food prices such as a $26 \%$ increase in the price of a gallon of whole milk from January 2007 to January 2008 or a 15\% increase in the retail price of bread from mid-2007 to mid-2008, and local newspapers such as 
the Sacramento Bee in California warned that "things like hamburger that used to be everyday food are becoming luxuries." While these food price increases pale in comparison to those reported in some developing countries, as documented in Ivanic, Martin and Zaman (2012), this evidence spurred new research on the pass-through from energy and agricultural commodity prices to the retail price of food in the United States (see, e.g., Leibtag 2009; Berck, Leibtag, Solis and Villas-Boas 2009; Roeger and Leibtag 2011).

The worldwide surge in food crop prices occurred at about the same time as a similar surge in the price of crude oil, raising the suspicion that oil and food crop prices have become more closely linked in recent years (see, e.g., Tyner 2010). Mallory, Irwin and Hayes (2012) provide evidence that this link was strengthened by the increased reliance on biofuels in industrialized economies, notably in the United States. While the United States traditionally had pursued policies favoring the production of ethanol from corn, a further shift in U.S. policy occurred in 2005 when policy-makers refrained from providing liability waivers for the use of the environmentally harmful gasoline additives traditionally used in producing high-octane fuels. ${ }^{1}$ This decision effectively made ethanol produced from corn the only gasoline additive available to U.S. refiners after May 2006. This shift in U.S. policy was followed by the introduction of renewable fuel standards mandating the use of ethanol in the production of gasoline. ${ }^{2}$ It was also followed by a surge in the price of corn and other crops, often collectively referred to as food commodities.

Many pundits agree that oil prices affect food prices in a variety of ways (see, e.g., Westhoff 2012). Some observers have gone as far as claiming that "food prices mirror oil prices"

\footnotetext{
${ }^{1}$ Corn in American English is maize in British English. We follow the American usage, given that our data are obtained from the U.S. Department of Agriculture.

${ }^{2}$ For a detailed review of the legislative process culminating in U.S. biofuel mandates see Anderson and Elzinga (2013); Carter, Rausser and Smith (2013); and Abbott (2013).
} 
(Dancy 2012). While the latter position does not seem tenable, there are good reasons to suspect a causal link. For example, corn is used both as food and as a raw material in producing ethanol. To the extent that the latter competes with crude oil in producing refined products such as gasoline and diesel, all else equal, one would expect higher oil prices to be reflected in higher corn prices. In addition, corn is also used to feed farm animals. The resulting increases in the cost of producing meat and dairy products puts upward pressure on meat and dairy prices. Moreover, corn competes with other agricultural commodities for fertilizer and for scarce water and land resources, adding to the pressure on food prices. Finally, the prices of all agricultural products will be affected to the extent that diesel is used to power mechanized farm equipment.

In fact, corn is but one example of a food commodity the price of which is directly linked to the price of crude oil. Additional examples include soybeans, which may be used to produce biodiesel or food; other oil seeds, which may be used to produce vegetable oil or biodiesel; and grains, which may be used to produce cereals or for heating buildings. The potential price pressures from rising oil prices are not limited to the production stage of food, however. Higher energy costs may also raise the cost of food processing, food packaging and distribution. In particular, the cost of transportation is a potentially important component of the price of food, as is the cost of producing plastic and foam packaging.

The objective of this paper is to examine what the evidence is for a link from oil prices to food prices. We are not the first to raise this question. There is a rapidly growing literature using time-series data to study the link between oil prices, agricultural commodity prices and food prices. The modelling techniques used and the main conclusions reached in this literature have been reviewed by Serra and Zilberman (2013). Much of this literature, however, is based on atheoretical time-series models that are inherently incapable of establishing or quantifying causal 
links in the data. ${ }^{3}$ Hence, claims in this literature about how oil prices "impact," "influence," "feed back to" or "drive" food prices must be discounted. What these studies document, at best, is that oil prices increased prior to food prices in recent years, but that observation is uncontroversial.

What is needed to quantify causal relationships between the price of oil and crop and food prices is a structural econometric framework that acknowledges the underlying identification problem. One concern is that there is not only causality running from oil prices to food prices, but also causality running in the other direction. A case in point is the dramatic shift toward more mechanized agricultural production in China in recent years. For example, the use of tractors (excluding small tractors) in China increased by 20\% in 2006, by $23 \%$ in 2007 and by $46 \%$ in 2008 . The reasons include a shortage of unskilled labor, as workers migrate to cities; higher farm incomes, which facilitate the purchase of machinery; and government subsidies for agricultural equipment. Such an expansion of agricultural activity involves a shift in the global demand for crude oil, invalidating the premise of one-way causality from the price of crude oil to agricultural commodity prices.

A second concern is that, even abstracting from reverse causality in agricultural commodity markets, the oil price increases after 2003 did not occur in isolation, but were the result of changes in the global economy. Thus we cannot treat these oil price increases as though they occurred all else equal, as many existing studies explicitly or implicitly do. An example illustrates this point. It has been shown that much of the surge in oil prices between 2003 and mid-2008 was associated with an unexpectedly booming world economy, notably in emerging Asia (see, e.g., Kilian and Hicks 2013; Kilian and Murphy 2013). This economic expansion was

\footnotetext{
${ }^{3}$ Examples are the use of so-called Granger non-causality tests as a means of establishing causality and the use of reduced-form VAR impulse responses or the interpretation of the coefficients of reduced-form vector errorcorrection models or autoregressive models as measures of causal impact.
} 
also associated with higher incomes in countries such as China, which caused higher demand for food in general and higher global demand for high-quality foods in particular including wine, meat and dairy products, for example. This shift in demand for food products, in turn, has affected the demand for agricultural commodities such as corn. For example, the U.S. grains council reported in 2013 that, for the first time in history, China is set to produce more corn than rice, reflecting a new pattern of demand. Thus, observed increases in food commodity prices are by no means attributable to the increase in the price of oil alone. Put differently, if the same increase in the real price of oil had been caused by oil supply disruptions in the Middle East, the response of food crop prices would have been quite different. Moreover, the precise causes of the observed surge in the real price of oil prices matters for the persistence of the response of oil and food prices.

A third concern is that the pass-through from oil prices to food prices depends on the reaction of the domestic central bank, as stressed by Hamilton (2012), making it more difficult to isolate empirically what is unique about the response of food prices.

The econometric analysis in this paper is designed to help us quantify many of the relevant channels of transmission in question, keeping in mind the complications discussed above. Our approach complements recent work in the resource economics literature that uses structural dynamic econometric models to quantify the effects of biofuel policies on agricultural commodity prices, with notable contributions by Hausman, Auffhammer and Berck (2012) and Carter, Rausser and Smith (2013). Their estimates of the effects of biofuel policies on crop prices range from less than $10 \%$ to $34 \%{ }^{4}$ In contrast, our work is not concerned with the effects of these policies as such, but with understanding the dynamic relationship between oil prices,

\footnotetext{
${ }^{4}$ Closely related work includes the comparative statics analysis of the effects of the 2009 renewable fuels standard in Roberts and Schlenker (2013) by means of a structural model of major agricultural commodity markets.
} 
agricultural prices and ultimately food prices, especially after the change in U.S. biofuel policies in 2006 .

The remainder of the paper is organized as follows. Section 2 reviews the salient data and highlights the facts to be explained. Section 3 shows how case studies may be used to gauge the impact of oil price shocks on food prices, while controlling for changes in global real economic activity. Section 4 examines the evidence for a structural break in the relationship between oil and food prices in May of 2006, when U.S. policy toward ethanol changed with the implementation of the Energy Policy Act of 2005, which established a closer link between oil prices and corn prices. The main results are reported in section 5, which attempts to gauge the quantitative importance of each of the main channels of transmission from oil price shocks to food prices. We distinguish in particular between the effect of real oil price shocks on the prices paid and received by U.S. farmers, on the one hand, and their effect on the cost of marketing food to retail customers in the U.S. on the other. Section 6 distinguishes between common and idiosyncratic determinants of global agricultural commodity prices and discusses implications of our evidence for developing economies. Concluding remarks are offered in section 7.

\section{Facts about Food Prices}

Consumers tend to be aware of rising food prices more than rising prices for other goods, with the possible exception of gasoline, because food items are purchased on a regular basis. Figure 1 plots the cumulative percent growth in U.S. consumer prices since May 2006 for all food items in the aggregate, as well as for the four most important components of food consumed at home. It shows that, overall, food prices have increased by $20 \%$ in only seven years. The price of cereals and baked goods increased even faster at a rate of almost $25 \%$, with the price of meats, 
poultry, fish and eggs close behind. The consumer price of the remaining items grew at a slower pace, but even the price of fruits and vegetables rose by $15 \%$ in only seven years.

This evidence confirms the impression that, indeed, food prices have been rising persistently in recent years. Of course, so have all prices. In fact, in a country with a moderate two percent rate of inflation one would expect all prices to increase by about $15 \%$ in seven years. Thus, the real question is whether food prices have increased more than other consumer prices. Figure 2 addresses this question by expressing the food prices underlying Figure 1 relative to an index of U.S. consumer prices excluding food. This transformation results in a measure of the real price of food that conveys how much consumers have to give up in terms of other consumer goods to purchase these food items. Figure 2 illustrates that, overall, the real price of food has increased by only $7 \%$ since May 2006 . This means that a household spending $\$ 1,000$ a month on food would have had to cut back other expenditures by $\$ 70$, provided that it cannot economize its expenditures by changing the composition of its food purchases or by reducing its overall food purchases. This aggregate result hides the fact that the price of some food items such as fruits and vegetables hardly changed, while others such as cereals and baked goods or meats, poultry, fish and eggs experienced double-digit percent price increases in real terms, but is nevertheless representative for the overall impact of food price inflation on retail consumers.

\subsection{Food Price Increases in Historical Perspective}

The evidence in Figure 2 raises several questions. One is how these price increases compare with historical experience. Another important question is how the prices faced by consumers compare with the prices paid and received by U.S. farmers, and how they compare with the price of crude oil and oil products such as diesel fuel. Table 1 provides a systematic comparison. It focuses on the price of crude oil and diesel fuel; the price paid by U.S. farmers for agricultural inputs such 
as fuel, fertilizer and animal feed; the price received by U.S. farmers for key agricultural products such as corn, wheat, soybeans and rice, and for livestock such as cattle, hogs, broilers and turkeys; and finally the price paid by U.S. consumers for food. The prices received by U.S. farmers closely mirror the spot prices quoted on commodity exchanges and reported by the International Monetary Fund. The data sources are described in the appendix. All prices in Table 1 have again been expressed in real terms by normalizing them relative to the index of U.S. consumer prices excluding food items. Table 1 contrasts the experience from January 1974 until April 2006 with that since May 2006.

Table 1 reveals some striking contrasts. Whereas, prior to May 2006, real retail food prices overall had been declining at the rate of $0.6 \%$ per year, they increased on average by $0.9 \%$ per year after May 2006. At the same time, the rate of growth in the real price of crude oil accelerated from $1.2 \%$ on average prior to May 2006 to $4.2 \%$ on average after May 2006. This evidence raises the question of whether there might be a relationship, as conjectured by many pundits.

Interestingly, the perhaps more-relevant increase in the real price of diesel fuel after May 2006 was only $2.2 \%$ per year on average, which is reflected in a $2.5 \%$ per year increase in farmer's fuel costs. By comparison, the real price of fertilizer increased much more than the cost of crude oil, as did the real price of animal feed. This pattern appears consistent with a shift in the demand for agricultural products and possibly with a shift in the composition of agricultural products after May 2006, and with an expansion into marginal farm land. Likewise, the real price increases for corn and soybeans and to a lesser extent for wheat and rice far exceed the increases in the real price of crude oil and farm fuel. These increases are all the more striking compared with the systematic declines characteristic of previous decades. The corresponding increases in 
the real price of livestock tend to be more modest, but again are striking in historical comparison.

The increases in the real price received by farmers for products such as corn, wheat, soybeans and rice can be reconciled with the modest increases in the real price of food after May 2006 by observing that these farm products account for only a small fraction of the retail cost of food products. Overall, agricultural products account for less than $20 \%$ of the cost of food to consumers, with the remainder accounted for by the cost of processing, packaging, advertising, transporting and distributing food to retail markets. For example, the share of livestock prices in the cost of meat to consumers may be as high as $50 \%$, while the share of wheat in the cost of bread historically has been only about $5 \% .{ }^{5}$ This means that, all else equal, a doubling of the price of wheat will be associated with only a $5 \%$ increase in the price of bread.

To summarize, Table 1 conveys that there is no evidence of a tight statistical relationship between oil prices and U.S. retail food prices, contradicting Dancy's (2012) claim that food prices mirror oil prices. Figure 3 illustrates the lack of fit. Whereas the real price of oil fluctuates within $+100 \%$ and $-100 \%$ of its long-run mean, the real price of food remains within a few percentage points of its mean. Not only are the magnitudes quite different, but the probability that the price of food increases when the price of oil increases is less than $47 \%$, indicating the absence of a systematic relationship. Moreover, there is no evidence that the fit improves after May 2006.

Table 1 shows a stronger statistical relationship between oil prices and the grain crop prices received by U.S. farmers, the reasons for which will be examined in more detail below. It is useful to examine the degree of co-movement of agricultural product and oil prices and the extent to which this co-movement has strengthened in recent years. Figure 4a compares the

\footnotetext{
${ }^{5}$ Detailed information about the farm value shares for selected food products are provided by the Economic Research Service of the U.S. Department of Agriculture (http://www.ers.usda.gov/data-products/price-spreads-fromfarm-to-consumer.aspx).
} 
evolution of the real price of corn, wheat and soybeans prior to May 2006 with that of the real price of oil. We exclude the real price of rice because of its lesser importance for U.S. agriculture and because one would not expect it to be linked as tightly to oil as some of the other grain prices. Whereas the real agricultural product prices show comparatively small variation about a declining trend, the real price of oil exhibits much larger variation about its long-run mean with no indication of a long-run trend. Figure $4 \mathrm{~b}$ shows that the secular decline in the agricultural product prices is reversed after May 2006 and the co-movement between the real price of oil and real agricultural product prices becomes more pronounced. This co-movement, however, remains far from perfect.

There are several potential explanations of this evidence. One possible explanation is that the increased co-movement reflects, first, increased demand for oil in emerging economies, followed by rising incomes and higher demand for agricultural products worldwide. Another potential explanation is that higher oil prices are associated with increased prices for agricultural inputs that drive up crop prices. A third and complementary potential explanation is that U.S. agricultural policies created a tighter link from oil prices to agricultural product prices. Finally, yet another possible explanation is the financialization of global commodity markets after 2003. Kilian and Murphy (2013), Kilian and Lee (2013), and Fattouh et al. (2013) show that this last explanation is not supported by oil market data, making it implausible that it would apply to other commodity markets, and allowing us to focus on the first three explanations. For more direct evidence on the role of financial speculation in the wheat market see Janzen, Carter, Smith and Adjemian (2013). 


\subsection{Has the Volatility of the Real Price of Food Increased?}

As discussed in the introduction, the premise of much of the policy debate has been that the volatility of food prices is said to have increased since the shift in U.S. biofuel policies. This fact is usually taken as self-evident. While several studies have reported evidence of rising food price volatility, that evidence in many cases is problematic from a statistical point of view. ${ }^{6}$ Table 1 shows that the premise of rising food price volatility is difficult to sustain. The last column of Table 1 reports the percent change in the volatility of the monthly growth rates in period (a), referring to January 1974 to April 2006, and period (b), referring to May 2006 to May 2013. For example, the volatility of the growth rate of the real price of oil increased by $31 \%$. This increase reflects the sharp drop in oil prices in late 2008 , following the financial crisis. There is no indication of increased volatility beyond this one episode.

If there were a close link from oil to food prices, one would expect a similar increase in volatility in agricultural crop prices. However, only the growth rate of wheat prices shows a similar increase in volatility, whereas that of corn prices increases by only $10 \%$, that of soybeans actually falls by $5 \%$ and that of rice falls by $30 \%$. This evidence argues against the view that price volatility in food commodities has risen systematically. Moreover, comparing wheat and corn, in particular, shows that the smaller volatility increases apply to the growth in the real price of corn which, according to conventional wisdom, should be most exposed to higher oil price volatility.

Likewise, with the exception of live turkeys, there is no evidence of an increase in the volatility of livestock prices. In fact, the price volatility for cattle declined by $10 \%$ and that for hogs declined by $15 \%$, again contradicting conventional wisdom. Finally, although the volatility

\footnotetext{
${ }^{6}$ For example, it is common to focus on nominal rather than real prices, to compute variances of non-stationary time series and to report correlations of trending data.
} 
of the growth rate of the real price of consumer food increased, it did so only by $10 \%$ compared with the $31 \%$ increase for crude oil. Volatility changes for components of the real food price index range from $-44 \%$ to $16 \%$, with the exception of food away from home, with a $70 \%$ volatility increase. This evidence is not supportive of a general increase in the volatility of retail food prices or of a spillover from oil price volatility to price volatility in agricultural markets.

Rather than relying on summary statistics, Figure 5 plots the percent growth rates of the real price of oil, the real price of corn and the real consumer price index (CPI) for food. To facilitate visual comparison, we show the data for exactly seven years before and after May 2006. One would be hard pressed to detect visually a substantial shift in volatility in May 2006 for any of these time series. Although there is an unusually large positive spike in consumer food prices in late 2008 , this spike is offset by lower volatility in subsequent years. This plot should put to rest the popular view that there has been a substantial increase in food price volatility in recent years. It is also noteworthy that the positive spike in the growth rate of real retail food prices coincides with a negative spike in the growth rate of the real price of oil, but that there is no large spike in either direction in the growth rate of the real price of corn.

\subsection{Has the Correlation between the Real Prices of Oil and Food Increased?}

A closely related position in the literature is that the positive correlation between percent changes in oil prices, on the one hand, and in agricultural commodity prices and retail food prices on the other has increased in recent years (see, e.g., 2011 Interagency Report to the G20, p. 10). Table 1 shows that, prior to May 2006, the contemporaneous correlation between the growth rate in the real price of crude oil and the growth rate in real agricultural crop prices ranged from -0.03 to -0.09. After May 2006, we find correlations ranging from -0.1 to 0.3 between the real price of oil and the real price of crops. To put these results in perspective, it is useful to compare these 
correlations with those between the growth rate in the real price of oil and the growth rate in the real prices farmers pay for fuel, fertilizer and animal feed. While the correlation of 0.85 for fuel matches that of diesel fuel, as expected, the correlations of 0.3 for animal feed and 0.12 for fertilizer are much more modest, arguing against a tight statistical link. Similar results apply to the growth rate in the real price of livestock, whose various correlations with the growth rate in the real price of oil range from -0.02 to 0.06 before May 2006 and between -0.03 and 0.26 after May 2006. Neither set of results provides strong evidence for a tight statistical link between growth in the real price of oil and in real agricultural prices.

Turning to the real retail price of food in Table 1, the results are even weaker. Prior to May 2006, the contemporaneous correlation between the growth rate in the real price of food and that in the real price of oil was -0.13 , meaning that there was essentially no linear relation. After May 2006 this correlation falls to -0.74 . In short, there is no support for the popular notion of a tight statistical link between increases in the real price of oil and increases in the real price of food. Of course, the absence of a positive contemporaneous correlation does not rule out the existence of a conditional correlation between these real prices such that an unexpected increase in the real price of oil is followed by a delayed positive response of the real price of food. This separate question will be examined in detail in section 5.

\section{A Case Study Approach}

Given that global demand shocks affect both the demand for agricultural products and the supply of agricultural products, one cannot interpret the co-movement of food and oil prices as evidence of a causal relationship. One potential solution to this problem would be to instrument for oil prices using oil supply shocks associated with unrelated political events in the Middle East. The objective of the use of these instruments is to isolate the component of the real price of oil that is 
not associated with unanticipated fluctuations in the global business cycle. The problem is that existing oil supply shock instruments are weak in the statistical sense. Their lack of predictive power for the real price of oil invalidates the use of conventional instrumental variable estimators (Kilian 2008a,b).

An alternative approach is to rely on case studies. Of particular interest is the sharp spike in oil prices that occurred after July 1990, when Saddam Hussein invaded Kuwait. It is well established that this major oil price spike was driven by oil supply disruptions and by concerns among oil market participants about pending additional oil supply shortfalls in case the war were to engulf Saudi Arabia. Put differently, this oil price spike was clearly not related to the strength of the global business cycle (see, e.g., Kilian and Murphy 2013). This means that we can think of this variation in the real price of oil as exogenous with respect to U.S. agricultural product markets.

If there is a relationship between oil prices and agricultural prices because higher prices for oil-intensive agricultural inputs push up the price of agricultural product prices, then this is the historical episode where we would expect to see a reaction in the cost of farm inputs such as fuel and animal feed, as well as in agricultural product prices. Figure 6a clearly shows a spike in the real price of oil in 1990, but no apparent response of real corn, wheat or soybean prices, demonstrating that there is no tight causal link between oil prices and agricultural commodity prices at least prior to May 2006. This finding is reinforced in Figure 6b which shows that only fuel prices, but not fertilizer or animal feed prices, responded to this exogenous oil price shock. This evidence means that proponents of such a causal link have to make the case that this link emerged only in recent years. A natural candidate for such a structural shift is changes in U.S. biofuel policies. 


\section{What Is the Evidence of a Structural Break Related to Increased U.S. Ethanol Production?}

Even though the evidence in Figure 4a shows that there has been no obvious link between oil and food prices historically, we have to allow for the possibility that the expansion of biofuel production after May 2006 has changed the link between oil and food prices in recent years. U.S. ethanol policies go back more than 30 years. An important change in U.S. policy took place with the passing of the Energy Policy Act of 2005. At the time, it was standard for gasoline producers to add organic compounds such as methyl tertiary butyl ether (MTBE) or ethanol to the gasoline produced by refineries to raise its octane rating to levels suitable for car engines. As discussed in Anderson and Elzinga (2013), these compounds also served as oxygenates that reduce the emissions of carbon monoxide, as required by the U.S. Environmental Protection Agency (EPA). Finally, in cities with particularly poor air quality, the EPA mandated that only reformulated gasoline be sold, which involves blending gasoline with either MTBE or ethanol.

In the late 1990s, MTBE was linked to the pollution of drinking water, prompting a number of U.S. states to ban its use after 2000. These bans effectively served as ethanol mandates at the state level, as shown in Anderson and Elzinga (2013), given that ethanol was the only available alternative means of satisfying the oxygenation requirement and of raising octane levels. Meanwhile, oil companies sought legal protection from MTBE-related lawsuits. When the Energy Policy Act of 2005 failed to grant a liability waiver for the use of MTBE in states not already subject to MTBE bans, gasoline producers chose to phase out MTBE completely. This decision had far-reaching implications for the price of corn, from which ethanol is primarily produced in the United States. For example, Carter, Rausser and Smith (2013) report that, by 2012, 40\% of U.S. corn was used to produce gasoline additives, up from only $14 \%$ in 2005 . 
In addition, Congress passed the Renewable Fuels Standard in 2005, which ensured a minimum demand for ethanol and contained additional provisions aimed at subsidizing ethanol production by offering tax credits and imposing import tariffs on ethanol. The latter provisions were dismantled only in 2011 and 2012. The required minimum levels of ethanol production were doubled by the Energy Independence and Security Act of 2007. Legislation regarding the use of ethanol continues to evolve. In 2015, the minimum on annual corn ethanol production is set to rise further to 15 billion gallons compared with 4 billion gallons in 2006 (Carter, Rausser and Smith 2013). Whereas, initially, environmental concerns were driving biofuels legislation, policy-makers' motives have evolved over time to include concerns about energy security and pressures from the agricultural lobby.

We treat May 2006 as the date of a tentative structural break in the relationship between oil, agricultural and food prices. There is no universal agreement on this date in the literature, but most observers agree that between late 2005 and late 2006 the link between crop prices and oil prices changed. For example, Carter, Rausser and Smith (2013) note that informed market participants would have been well aware by late 2006 of the impending boom in ethanol production, and Mallory, Irwin and Hayes (2012) document a change in the statistical relationship between corn and ethanol futures prices beginning in mid-2006.

Figure 7a shows the percent deviation of the real price of oil from the real price of corn. There is little evidence of a mean-reverting statistical relationship, as one would expect, given the secular decline in corn prices. This concern may be addressed by removing a deterministic time trend from the spread between January 1974 and April 2006, as shown in Figure 7a, but visual inspection suggests that even in the latter case a common trend, if indeed such a trend exists, must be very weak given repeated substantial and persistent deviations from trend. When 
fitting a common trend to oil and corn prices since May 2006, as shown in Figure 7b, in contrast, the deviations from the long-run mean appear somewhat smaller and less noisy. One way of making these impressions more formal is to compute measures of the directional accuracy of changes in the real price of oil for changes in the real price of corn. It can be shown that prior to May 2006 the probability that the price of oil and the price of corn move in the same direction is only $51 \%$, where $50 \%$ is the benchmark value of this probability in the absence of a systematic relationship. After May 2006, in contrast, this probability rises to $60 \%$ and becomes statistically distinguishable at the $10 \%$ level from the hypothesis of purely random co-movement. ${ }^{7}$

One possible source of this co-movement after 2006 is a link between the real price of oil and that of agricultural inputs. Figure 8 suggests a tight link between the real price of diesel fuel and the real price of fuel paid by U.S. farmers. There is also a somewhat less tight statistical link between the real price of oil and the real price of fertilizer. Finally, there is an even weaker link between the real price of oil and the real price of animal feed. This evidence of a statistical relationship after May 2006 is consistent with the hypothesis of higher demand for agricultural products from emerging economies, as well as explanations based on a shift in U.S. agricultural policy.

To conclude, there is at least some evidence of non-random co-movement after May 2006 between the real price of crude oil and the real price of corn, on the one hand, and between the real price of oil and the real price of agricultural inputs such as fuel, fertilizer and, to a lesser extent, animal feed on the other. The next section attempts to disentangle the channels of transmission from the real price of oil to raw agricultural product prices and, ultimately, retail food prices in more detail, taking account of the three potential explanations of such a link

\footnotetext{
${ }^{7}$ This assessment is based on the statistical test for directional accuracy proposed in Pesaran and Timmermann (2009).
} 
outlined earlier. Our focus is on responses to real oil price shocks obtained from structural vector autoregressive (VAR) models rather than the unconditional co-movement in the data. These models differ from atheoretical time-series models in that they impose additional identifying restrictions motivated by economic reasoning and extraneous empirical evidence.

\section{Quantifying the Channels of Transmission}

One way of trying to make sense of the many different potential channels of transmission is to break them into many smaller questions. This section examines various links in the chain from oil to food prices in a way that avoids some of the pitfalls in earlier empirical studies. Structural impulse-response analysis helps quantify each of the effects. Our baseline results are based on bivariate autoregressions. Throughout the paper, we use six lags to avoid well-known problems of post-model selection inference. Our empirical results tend to be qualitatively robust to using 12 lags and to the treatment of seasonality. ${ }^{8}$ We postulate that global crude oil prices are predetermined with respect to U.S. agricultural and food prices, which allows us to study the response of the latter prices to oil price shocks using semi-structural vector autoregressions. The assumption of predetermined oil prices means that unpredictable changes in the real price of oil affect agricultural and food prices within the current month, but are not themselves subject to instantaneous feedback from agricultural and food prices. This assumption is consistent with evidence in Kilian and Vega (2011) on the lack of instantaneous feedback from news about U.S. macroeconomic aggregates to the price of oil and to the price of gasoline. The assumption has

\footnotetext{
${ }^{8}$ A potential concern in studying the pass-through of oil prices to diesel fuel prices and ultimately to food prices is a possible asymmetry in the relationship between oil and fuel prices. There is a long-standing perception that oil price increases are followed by immediate increases in fuel prices, while oil price declines are transmitted to fuel prices only with a delay. Whether this perception is supported by the data continues to be debated. The evidence appears to be stronger in data at daily or weekly frequency than at monthly frequency. Building on methodological advances on Kilian and Vigfusson (2011), Venditti (2013) recently has shown that, in monthly data, there is no statistically significant evidence that fuel prices respond asymmetrically to positive and negative oil price shocks. We therefore ignore possible asymmetries in our analysis.
} 
been used widely in the literature in many contexts (see, e.g., Edelstein and Kilian 2009). ${ }^{9}$ It is important to note that our sample sizes are too short for any model larger than a bivariate model to be employed. For example, the fully structural VAR approach of McPhail (2011), which in turn builds on Kilian (2010), would be infeasible on data since May 2006.

\subsection{Quantifying the Pass-Through from Oil Prices to Food Prices}

In examining the relationship of oil and food prices, a natural starting point is to determine the pass-through of unanticipated changes in the real price of oil to the real price of food paid by U.S. consumers. We address this question by fitting the VAR model

$$
\left(\begin{array}{c}
p_{t}^{\text {crude/CPI }} \\
p_{t}^{\text {food CPI/CPI ex food }}
\end{array}\right) \sim \operatorname{VAR}(6),
$$

where $p_{t}$ denotes any real price expressed in logs and 6 refers to the number of autoregressive lags. All models include an intercept and are estimated by the method of unrestricted least squares. The real price of oil is measured in terms of the overall U.S. consumer price index, given that crude oil is not part of the consumption basket. The real price of food is measured relative to the CPI excluding food. This fact allows us to abstract from any general inflationary effects associated with oil price shocks and to focus on the perception that the response of food prices is unusual. One of the concerns in measuring the pass-through from oil prices to consumer prices, recently reiterated by Hamilton (2012), is that the extent of the pass-through depends on the response of the central bank to the inflationary pressures often associated with an oil price shock. By expressing the consumer price of food relative to other consumer prices, we effectively control for this monetary policy response which affects all consumer prices across the board.

\footnotetext{
${ }^{9}$ To conserve space, in the analysis below, we do not display the own-responses of the real price of oil. It can be shown that these responses are very similar across alternative model specifications for any given sample period.
} 
Throughout the paper, the VAR models are specified in log-levels. ${ }^{10}$ When plotting the results, we scale the responses, so that oil price shocks are associated with an unanticipated $1 \%$ increase in the real price of oil on impact. To allow for the structural change discussed in section 4, we present separate estimates for the period from January 1974 to April 2006 and from May 2006 to May 2013. Figure 9 plots the estimated impulse-response functions for a horizon from 0 to 17 months. It also plots $90 \%$ confidence intervals for each horizon that convey the precision of the estimates. ${ }^{11}$ The left panel shows that, between January 1974 and April 2006, an unanticipated $1 \%$ increase in the real price of oil, on average, has been associated with a statistically significant decline in the real price of food. In contrast, after 2006, the response of the real price of food changes. The real price of food initially drops sharply and significantly. In months 1 and 2 following the oil price shock, the real price of food drops to $-0.05 \%$. This decline is followed by a recovery that culminates in a statistically significant peak of the real price of food of $0.04 \%$ after 12 months.

At first sight, the initial drop in the real price of food may seem unexpected. The reason is that in these initial months the real price of gasoline in the consumer basket increases faster than the real price of food, so food becomes relatively less expensive, if only because gasoline is even more expensive. We can control for this effect by fitting the alternative VAR model

$$
\left(\begin{array}{c}
p_{t}^{\text {crude/CPI }} \\
p_{t}^{\text {food CPI/CPI ex food and energy }}
\end{array}\right) \sim \operatorname{VAR}(6),
$$

where the price of food has been measured relative to the CPI excluding food and energy. This

\footnotetext{
${ }^{10}$ This specification is chosen to ensure consistency of the estimates regardless of the possible cointegration of the model variables (Sims, Stock and Watson 1990; Inoue and Kilian 2002). Our approach also avoids the well-known problems associated with pre-tests for unit roots and cointegration in VAR models (see Elliott 1998). The superior accuracy of the log-levels approach in small samples has recently been demonstrated in Gospodinov, Herrera and Pesavento (2013).

${ }^{11}$ The confidence intervals for the impulse responses are constructed using a recursive-design wild bootstrap method, as proposed in Goncalves and Kilian (2004). This bootstrap method allows for conditional heteroskedasticity of unknown form in the data.
} 
alternative definition measures how expensive food is compared to other consumer prices, excluding gasoline in particular. Figure 10 shows that the declining response of the real price of food to a $1 \%$ unanticipated increase in the real price of oil prior to May 2006 is statistically insignificant, while the response after May 2006 now is hump-shaped with a statistically significant peak of $0.05 \%$ after 10 months. This evidence supports the notion of a statistically significant relationship between oil price shocks and food prices after May 2006 and the absence of such a relationship prior to May 2006. It is useful, however, to keep in mind that the increases in question are small in magnitude. For example, a household spending $\$ 1,000$ on food per month after an unexpected $100 \%$ increase in the real price of oil, all else equal, would have to cut back its expenditures by $\$ 50$ ten months later. The small magnitude of these responses is consistent with the evidence in Figure 3 that food prices have remained rather stable throughout our sample, even as the real price of oil has fluctuated wildly.

It is useful to decompose these results further. Figure 11 provides analogous results for the eight major components of U.S. food expenditures. All food prices are measured relative to the CPI excluding food and energy. There is evidence of statistically significant increases in the real price of cereals and baked goods, meats/poultry/fish/eggs, dairy, other food at home, and food away from home. The response of expenditures on fruits and vegetables is positive, but not statistically significant. There are no large or statistically significant responses in non-alcoholic beverages and alcoholic beverages.

\subsection{Understanding the Pass-Through from Oil Prices to Food Prices}

It is instructive to examine in more detail how oil price shocks are transmitted to food prices at different stages of the production of food. One obvious source of higher food prices are increases in the prices of raw agricultural products driven by higher oil prices. 
There are several channels by which higher oil prices may be transmitted to the prices of raw agricultural products. For example, it is common to assert that the price of corn in particular is sensitive to the price of oil because of the use of corn in producing ethanol. Upon reflection, this link is far from obvious. Much depends on why the real price of oil increases. Gasoline producers blend low-octane gasoline with high-octane ethanol in approximately fixed proportions. ${ }^{12}$ If the real price of oil increases unexpectedly because of a supply disruption in the Middle East, for example, this will not increase the demand for corn. If anything, it will lower the demand for gasoline and hence for corn over time, as economic growth slows down and therefore gasoline demand diminishes.

In contrast, in response to an unexpectedly booming world economy, one would expect gasoline demand to expand, shifting the derived demand for corn as well as crude oil. In the latter case, one would expect positive shocks to the real price of oil to be followed by increases in the real price of corn. This response occurs not because higher oil prices cause higher corn prices, but because both share a common macroeconomic determinant. This is the central message of studies that have shown that recent oil price fluctuations in large part are explained by shifts in demand from emerging economies (see, e.g., Kilian and Murphy 2013; Kilian and Hicks 2013). To the extent that the global economic expansion underlying the 2003-2008 oil price increase is associated with a reduction in gasoline consumption in the United States, however, even this link is severed, except to the extent that the United States exports ethanol and/or ethanol-gasoline blends.

More generally, the macroeconomic determinants of the real price of oil would also be

\footnotetext{
${ }^{12}$ These proportions have evolved somewhat over time in response to changes in fuel standards. Abstracting from the smaller market segment for reformulated gasoline, gasoline producers currently have converged on a profitmaximizing strategy of blending 84 octane gasoline produced by refineries with 115 octane ethanol to produce 87 octane regular gasoline at the pump (Babcock 2013, p. 3).
} 
expected to raise the real price of wheat and soybeans, although not to the same extent, as higher incomes in emerging economies alter food consumption patterns. A related indirect channel by which higher oil prices may be associated with higher agricultural prices involves competition for scarce resources, such as water and agricultural land, in response to a shift in the demand for corn. Of course, this effect arises only if the underlying oil price shock is associated with higher demand for corn.

To summarize, only to the extent that there is flexibility in substituting ethanol for lowoctane gasoline would we expect higher crude oil prices, all else equal, to raise the demand for corn and hence the real price of corn. Such flexibility existed only intermittently after May 2006, limiting the scope for large responses in the demand for crops. This is not the only channel of transmission, however. Another direct channel of transmission, which applies even in the case of oil price increases driven by oil supply shocks, involves increases in the cost of producing agricultural products. Of particular importance are increases in the cost of farm fuel associated with higher oil prices.

Although the notion that higher oil prices are passed through to agricultural crop prices is intuitive, there are some important caveats. For example, this argument does not apply to the cost of fertilizer. Whereas the cost of farm fuel closely mimics the price of diesel fuel and hence depends directly on the price of crude oil, nitrogen fertilizer is produced from natural gas rather than crude oil. ${ }^{13}$ Even before 2008, the prices of natural gas did not always follow the price of crude oil, but after 2008 even the long-run statistical relationship between these prices collapsed with the development of shale gas in the United States. While the real price of crude oil recovered, the real price of natural gas plummeted and the cost of fertilizer decoupled from the

\footnotetext{
${ }^{13}$ U.S. agriculture depends on nitrogen-based fertilizers, the production of which requires natural gas as the primary source of hydrogen for reaction with nitrogen to yield ammonia. The cost of natural gas accounts for $70 \%-80 \%$ of the cost of nitrogen-based fertilizer.
} 
price of crude oil. This means that the direct effect of higher oil prices on the cost of agricultural production is effectively bounded by the cost share of fuels in agriculture. Even granting that this cost share has increased with the surge in fuel prices after 2003, this limits the potential effects of real oil price shocks. Sands and Westcott (2011) report that direct energy use (including not only fuels, but also electricity and natural gas) accounted for $6.7 \%$ of total production expenses in the U.S. farm sector in 2005-08. A doubling of diesel fuel prices, on the basis of these estimates, would be associated with perhaps a 5\% increase in farm production costs.

These considerations suggest that the scope for the transmission of real oil price shocks to the real price of agricultural commodities is limited. While there has been a shift in the real price of corn in recent years associated with a one-time persistent shift in the demand for corn, the debate continues as to how much of that shift was associated with biofuel subsidies, the prohibition of MTBE, and renewable fuel mandates, and how much of it occurred because ethanol production became viable as a cost-effective alternative to crude oil, as the real price of oil surged (Babcock 2013). This analysis is further complicated by the fact that, once the initial investment in expanding ethanol capacity has taken place, continued ethanol production only requires the price of ethanol to exceed its marginal cost.

Our analysis focuses on the narrower question of how much of the increase in the real price of corn after May 2006 was systematically related to real oil price shocks. In the interest of parsimony, our econometric analysis below ignores non-linearities in the corn and ethanol market that may arise from shifts in capacity constraints (see, e.g., Abbott 2013). Our linear regression models provide a first-order approximation to the average response during this period of real agricultural prices to unexpected changes in the real price of oil. 


\subsubsection{How Different Is Corn?}

A common conjecture is that, after May 2006, oil price shocks raised the price of corn relative to other agricultural commodities that cannot be used to produce gasoline additives. The reason is that presumably higher demand for oil during this period was associated with higher demand for corn used in producing ethanol only after May 2006. This concern may be examined using the model

$$
\left(\begin{array}{l}
p_{t}^{\text {crude/CPI }} \\
p_{t}^{\text {corn } / \text { wheat }}
\end{array}\right) \sim \operatorname{VAR}(6)
$$

which relates the price of corn to that of wheat. The left panel of Figure 12, which focuses on the period of January 1974 through April 2006, shows a statistically insignificant decline in the price of corn relative to the price of wheat following a $1 \%$ unexpected increase in the real price of oil. After May 2006, as shown in the right panel, the response to a $1 \%$ unexpected increase in the real price of oil is positive, as conjectured, with a peak response near $0.4 \%$, but the responses are all statistically insignificant.

Wheat was chosen as the benchmark in Figure 12 because it is less prone than corn to be used as a biofuel. In contrast, soybeans have played an increasingly important role in the production of biodiesel after 2006, so the effect of real oil price shocks on this relative price is ambiguous ex ante. A similar exercise involving the model

$$
\left(\begin{array}{c}
p_{t}^{\text {crude/CPI }} \\
p_{t}^{\text {corn/soybeans }}
\end{array}\right) \sim \operatorname{VAR}(6)
$$

indicates that soybean prices have been less responsive to oil price shocks in recent years than corn prices. Figure 13 shows no statistically significant response of the price of corn relative to soybeans prior to May 2006, as expected, but a statistically significant hump-shaped response 
with a peak of $0.4 \%$ after May 2006 .

\subsubsection{The Response of Prices Received by U.S. Farmers}

Figure 14 shows how sensitive the real price of corn, wheat, soybeans and rice

received by U.S. farmers has been to oil price shocks before and after May 2006. The premise of many policy studies has been that one would expect a larger response after May 2006 for corn, and for crops that compete with corn for land and water, because of the shift in U.S. biofuel policies. We estimate the models

$$
\left(\begin{array}{c}
p_{t}^{\text {crude/CPI }} \\
p_{t}^{\text {corn } / C P I}
\end{array}\right) \sim \operatorname{VAR}(6), \quad\left(\begin{array}{c}
p_{t}^{\text {crude/CPI }} \\
p_{t}^{\text {wheat } / C P I}
\end{array}\right) \sim \operatorname{VAR}(6), \quad\left(\begin{array}{c}
p_{t}^{\text {crude/CPI }} \\
p_{t}^{\text {soybeans/CPI }}
\end{array}\right) \sim \operatorname{VAR}(6), \quad\left(\begin{array}{c}
p_{t}^{\text {crude/CPI }} \\
p_{t}^{\text {rice/CPI }}
\end{array}\right) \sim V A R(6)
$$

for the time periods before and after May 2006. There is no evidence of a statistically significant response of the real price of any of these crops prior to May 2006. After May 2006, the responses of all four real crop prices to a real oil price shock are larger and consistently positive. The real price of corn exhibits the largest, most persistent and most statistically significant response. The peak response after about one year is $0.7 \%$. The peak response of the real price of soybeans of $0.5 \%$ occurs already after four months and is marginally statistically significant. The response of the real price of wheat is more delayed, reaches a peak of $0.4 \%$ after about one year and is statistically insignificant. Finally, the real price of rice shows a statistically significant peak response of $0.45 \%$ after eight months. This evidence is consistent with the perception that, after May 2006, at least the real prices of corn and rice (and, to a lesser extent, the real price of soybeans) have been sharing a common determinant with the real price of oil. In section 6 , we investigate this common component in more detail.

Figure 15 focuses on the evolution of the real price of livestock received by U.S. farmers in response to a $1 \%$ real oil price shock. Estimates of the models 


$$
\left(\begin{array}{l}
p_{t}^{\text {crude/CPI }} \\
p_{t}^{\text {cattle/CPI }}
\end{array}\right) \sim \operatorname{VAR}(6) \quad\left(\begin{array}{c}
p_{t}^{\text {crude/CPI }} \\
p_{t}^{\text {hogs/CPI }}
\end{array}\right) \sim \operatorname{VAR}(6) \quad\left(\begin{array}{c}
p_{t}^{\text {crude/CPI }} \\
p_{t}^{\text {broiler/CPI }}
\end{array}\right) \sim \operatorname{VAR}(6) \quad\left(\begin{array}{l}
p_{t}^{\text {crude/CPI }} \\
p_{t}^{\text {turkey/CPI }}
\end{array}\right) \sim \operatorname{VAR}(6)
$$

suggest that, prior to May 2006, there is no evidence of a statistically significant response to real oil price shocks. The missing result for the real price of broiler chicken reflects gaps in the data. Fitting the same models on data after May 2006, to the extent that we can compare, all response estimates are larger than before, indicating a strengthening of the relationship between real oil price shocks and real livestock prices. The response of the real price of turkey is large and statistically significant, with a peak value of $0.7 \%$ after three months. The positive response of the real price of hogs, with a peak value of $0.3 \%$, is smaller, but statistically significant; that of the real price of cattle is in between, with a peak value of $0.5 \%$, but is statistically insignificant.

\subsubsection{The Response of Prices Paid by U.S. Farmers}

The responses in section 5.2.2 may reflect the use of grain crops in the production of biofuels, they may reflect a shift in the demand for agricultural commodities not related to biofuels or they may reflect the increases in the cost of agricultural production associated with higher oil prices. The link between the price of crude oil and the cost of fuel is self-evident. To the extent that higher oil prices inflate crop prices, they also directly increase the cost of animal feed, and higher demand for agricultural products may be associated with higher fertilizer prices. Fitting the models

$$
\left(\begin{array}{c}
p_{t}^{\text {crude/CPI }} \\
p_{t}^{\text {fertilizer/CPI }}
\end{array}\right) \sim \operatorname{VAR}(6), \quad\left(\begin{array}{c}
p_{t}^{\text {crude/CPI }} \\
p_{t}^{\text {fuel/CPI }}
\end{array}\right) \sim \operatorname{VAR}(6), \quad\left(\begin{array}{c}
p_{t}^{\text {crude/CPI }} \\
p_{t}^{\text {feed } / C P I}
\end{array}\right) \sim \operatorname{VAR}(6)
$$

on data since May 2006 allows us to investigate the response of the real price of fertilizer, of fuels used on farms and of animal feed paid by U.S. farmers, as reported by the U.S. Department of Agriculture, to a 1\% real oil price shock. Figure 16 confirms that all three real cost measures have tended to increase significantly in response to oil price shocks after May 2006. 


\subsection{Revisiting the Identification Problem}

An obvious concern is that unanticipated changes in the real price of oil may simply reflect higher demand for oil in a booming economy (Kilian and Murphy 2013). Such a situation complicates the interpretation of the responses to this type of shock because higher demand for oil often coincides with, or is followed by, higher demand for agricultural and food commodities, as discussed earlier. If we are interested in the causal effects of unexpectedly higher oil prices all else equal, we need to control for such shifts in the global demand for commodities.

One potential solution to the problem of isolating the effects of higher oil prices in the absence of global demand shifts would seem to be focusing on the excess of diesel prices over crude oil prices. In general, the price of crude oil and the U.S. price of diesel fuel tend to move in the same direction (Kilian 2010). A temporary wedge between these prices may nevertheless arise from shocks to U.S. refining capacity, as occurred with the refinery outages during Hurricanes Rita and Katrina, which sharply raised the price of refined products such as diesel fuel in the United States, with little effect on the global price of crude oil (Kilian 2010). Similar spikes may arise from unscheduled refinery shutdowns for maintenance or refinery fires, for example. In addition, a wedge may arise from changes in government regulation or even idiosyncratic shifts in U.S. demand or European demand for diesel fuel (Baumeister, Kilian and Zhou 2013). From the viewpoint of U.S. farmers and U.S. consumers, the impact of excess variability in the price of diesel is similar to an oil price shock, except that it does not involve a simultaneous change in the global demand for food and agricultural crops by construction.

This observation suggests that one could interpret the unexpected variation in the U.S. diesel price spread as a domestic diesel price shock, which may reflect either exogenous variation in U.S. refining or U.S.-specific variation in the demand for U.S. diesel fuel. If one 
were to find that food prices significantly respond to diesel price spread shocks, one could conclude that higher oil prices cause higher crop prices and food prices. If there were no such effect, our earlier evidence in support of such a link would seem to reflect shifts in the global demand with no independent role for oil prices.

Although this strategy sounds appealing at first, it is not recommended, as

illustrated in Figure 17, which plots the U.S. diesel fuel price spread since May 2006, providing an indication of its variation over time. The most notable feature of the data is a large spike in the diesel price spread in 2008/2009 at the time of the financial crisis. This spike does not reflect an idiosyncratic increase in U.S. diesel prices, however, but rather the fact that the global price of crude oil fell and recovered much faster than the U.S. price of diesel fuel, when global demand for oil first dropped dramatically and then rapidly recovered (Kilian and Lee 2013). Because this spike is negatively correlated with the global business cycle, an obvious concern is that regression-based estimates of the effects of unexpected variation in the diesel spread will reflect in part the effects of the financial crisis on demand for food and agricultural products. We therefore do not pursue this approach. ${ }^{14}$

Even though our estimates do not control for the effects of shifts in global demand on crop prices and oil prices, it is clear that doing so would only diminish the already very small responses of food prices associated with unexpected variation in the real price of oil. In this sense, it seems safe to ignore this issue in the context of our empirical analysis. This argument does not apply to the response of crop prices, however, which indeed may reflect global demand shocks for commodities as much as, or more than, other explanations.

\footnotetext{
${ }^{14}$ One could have conducted a case study along these lines of the effect on the price of food of Hurricanes Rita and Katrina, which provide a clean example of an exogenous shift in the diesel price spread. We do not pursue this question here because these events predate the shift in biofuel policies in May 2006 and we already ruled out a link from exogenous variation in the real price of oil to crop prices for that period in Figure 6.
} 
To gauge the role of global demand shifts in explaining the responses of crop prices to real oil price shocks, we can turn to a different source of identifying information. As discussed in section 5.2, we know that the production of nitrogen fertilizer relies on natural gas rather than crude oil. We also know that the real price of natural gas at the wellhead has fallen dramatically in recent years. Hence, the cost-push effect from higher oil prices on the real price of fertilizer must be negligible. Figure 16, however, shows a statistically significant positive response of the real price of fertilizer to a $1 \%$ real oil price shock, which can only be explained by a simultaneous shift in the demand for agricultural commodities and for oil. This fact in turn suggests that the positive responses of the real fuel price and of the real price of animal feed also reflects in large part the same demand shift, as do the responses of the agricultural prices in Figures 14 and 15. This observation is also consistent with the fact that the response of the real price of rice in Figure 14 is quite similar to that of the real price of corn, even though the production of rice should be largely unaffected by shifts in the demand for corn because rice production is water-intensive and highly concentrated in a few areas of the United States.

In other words, there is no compelling evidence that unexpected changes in the real price of oil alone and all else equal would have caused a change in agricultural product prices after May 2006. This conclusion is consistent with the evidence in Figure 6 based on data prior to May 2006. We defer further investigation of this point to section 6 . The following subsection focuses on an alternative channel by which real oil price shocks may affect retail food prices.

\subsection{Quantifying the Effect of a Higher Cost of Food Marketing on Retail Food Prices}

One of the main reasons why retail food prices are considered sensitive to the price of oil is that consumer prices for food are thought to depend on the cost of food processing, packaging, advertising, transportation and distribution (collectively referred to as food marketing). Because 
the distribution of fresh food by truck in particular relies on diesel fuel, one would expect the spread between retail prices for food and the prices received by farmers to be particularly responsive to oil price shocks.

Our analysis of this question differs from earlier work including Leibtag (2009), Berck, Leibtag, Solis and Villas-Boas (2009), and Roeger and Leibtag (2011) in that we quantify these dynamic effects using structural vector autoregressions estimated on data since May 2006. One way of capturing the response of this spread to oil price shocks is to match specific food items in the CPI and in the producer price index (PPI). We focus on dairy products including whole milk, butter, cheese and ice cream, which require refrigeration and hence are particularly energy intensive in transportation.

Our analysis involves fitting for each food item models of the form

$$
\left(\begin{array}{c}
p_{t}^{\text {crude/CPI }} \\
p_{t}^{\text {CPI dairy food item }}-p_{t}^{\text {PPI dairy food item }}
\end{array}\right) \sim \operatorname{VAR}(6) .
$$

Because these dairy products are already processed, this exercise primarily tells us about how sensitive the cost of transportation and distribution is to oil price shocks. Figure 18 shows that in no case is an unanticipated $1 \%$ increase in the real price of oil associated with an increase in the spread of consumer over producer prices, contradicting the notion that higher energy costs in transportation and distribution are being passed on from producers to consumers.

Figure 19 focuses on the corresponding spread between the retail price of processed dairy products paid by consumers and the price of milk received by U.S. farmers. The model is

$$
\left(\begin{array}{c}
p_{t}^{\text {crude/CPI }} \\
p_{t}^{\text {CPI dairy food item }}-p_{t}^{\text {farmers' milk price }}
\end{array}\right) \sim \operatorname{VAR}(6) .
$$

Unlike Figure 18, this exercise also incorporates the cost of producing these dairy products from the raw milk sold by the farmer. Figure 19 shows that even in this case there is no evidence that 
the cost of processing dairy food is increasing in response to real oil price shocks. Rather, there is evidence of a significant decline in this spread in the short run. Subsequent increases are small and statistically insignificant.

Even more-specific data on the components of food prices are available from the U.S. Department of Agriculture (USDA), which keeps track of the farm-to-wholesale price spread and the wholesale-to-retail price spread for pork and for beef sold in the United States. Rather than relying on the spread data provided by the USDA, we recompute the spreads in question as log deviations of the raw price indices provided by the USDA to ensure the stationarity of the spread data. The models are

$$
\left(\begin{array}{c}
p_{t}^{\text {crude/CPI }} \\
p_{t}^{\text {wholesale/net farm value }}
\end{array}\right) \sim \operatorname{VAR}(6) \quad\left(\begin{array}{c}
p_{t}^{\text {crude/CPI }} \\
p_{t}^{\text {retail/wholesale }}
\end{array}\right) \sim \operatorname{VAR}(6)
$$

Figure 20 shows that, if anything, the farm-to-wholesale spread declines in response to a real oil price shock, as does the wholesale-to-retail spread. There is no evidence that positive shocks to the real price of oil are associated with increases in the retail price of beef or pork associated with higher costs of processing, transportation or distribution.

Figure 21 shows results of a complementary exercise focusing on the spread between the consumer price for a whole fresh chicken and the price U.S. farmers receive for a broiler chicken, according to the USDA. There is no statistically significant increase in this spread in response to a real oil price shock. We also examined the spread between the price a consumer pays for poultry other than chicken (which includes turkey) and the price U.S. farmers receive for a live turkey. These responses again show a statistically significant decline rather than increase.

Figure 22 examines the same question using yet another source of data. We evaluate the 
response to a real oil price shock of consumer prices for flour, bread and breakfast cereal measured relative to the price of wheat received by U.S. farmers. The models are

$$
\left(\begin{array}{c}
p_{t}^{\text {crude/CPI }} \\
p_{t}^{\text {CPI flour/wheat }}
\end{array}\right) \sim \operatorname{VAR}(6) \quad\left(\begin{array}{c}
p_{t}^{\text {crude/ } / \text { PI }} \\
p_{t}^{\text {CPI bread/wheat }}
\end{array}\right) \sim \operatorname{VAR}(6) \quad\left(\begin{array}{c}
p_{t}^{\text {crude//CPI }} \\
p_{t}^{\text {CPI cereal/wheat }}
\end{array}\right) \sim \operatorname{VAR}(6) .
$$

Because wheat is one of the main agricultural inputs in producing flour, bread and breakfast cereal, one would expect higher processing, transportation and distribution costs driven by higher oil prices to translate into higher spreads. Figure 22 shows no evidence of such an increase in the spread in response to real oil price shocks, confirming the earlier results.

We conclude that there is no evidence to support the notion that oil price shocks are associated with increased food prices driven by higher costs of food processing, packaging, advertising, transportation and distribution. This result is not unexpected, because we already showed that food prices have been remarkably unresponsive overall to oil price shocks even after May 2006. To the extent that there is any response at all, it appears to be driven by higher crop prices.

A final question, that is not so much related to the price of food but to the price of serving food, is whether a real oil price shock drives up the cost of eating out compared with eating at home. Figure 23 reports results based on the model

$$
\left(\begin{array}{c}
p_{t}^{\text {crude/CPI }} \\
p_{t}^{\text {CPI food away/CPI food at home }}
\end{array}\right) \sim \operatorname{VAR}(6) \text {. }
$$

If higher oil prices were associated with higher costs of running restaurants, one would expect this spread to increase in response to a $1 \%$ real oil price shock. Figure 23 shows that the response instead appears to be significantly negative, allowing us to rule out this interpretation. 


\section{A Global Perspective}

Our results are in striking contrast with the literature and public debate on the emergence of global food shortages. It has been common in this debate simply to equate food prices with the prices of key agricultural commodities such as wheat, corn and soybeans. For example, Bruno, Büyükşahin and Robe (2013) discuss the evidence for speculation "in food markets." A casual observer might associate their work with retail food prices, when this study is actually concerned with the prices of grains and livestock traded on futures exchanges. Our analysis shows that care must be exercised in drawing a distinction between the prices of raw agricultural products and the retail price of food.

Whereas the response of real retail food prices to real oil price shocks has been negligible even after May 2006, as shown in Figure 10, we document much larger responses of the real price of food crops such as corn, wheat, soybeans and rice in Figure 14. To the extent that consumers in developing countries eat less processed food than U.S. consumers, the real price of crops is likely to be more representative for food prices in developing countries than in the United States. This observation suggests that we examine in more detail how sensitive real grain prices in particular are to real oil price shocks.

It is important to remind ourselves that the response estimates in Figure 14 need not represent the causal effects of real oil price shocks. A causal interpretation would require that shocks to the real price of oil are exogenous with respect to agricultural markets and occur all else equal. This premise seems unlikely, given the consensus in the literature that recent fluctuations in the real price of oil mainly arose because of unexpected variation in the global business cycle. Kilian and Hicks (2013), Kilian and Murphy (2013), and Kilian and Lee (2013), among others, demonstrate that the real oil price shocks since 2003 have reflected primarily 
global shocks to the flow demand for oil associated with unexpected industrial growth in emerging Asia. The same growth is likely to be followed by higher incomes in emerging Asia and hence by higher demand for high-quality food. Thus, an alternative interpretation is that increases in the real price of oil and increases in real crop prices in recent years have shared a common component that is associated with fluctuations in the global real activity and incomes.

\subsection{Are Crop Price Increases Associated with Shifts in Global Real Activity?}

We examine this question by relating changes in the real price of crops to flow demand shocks for crude oil and other industrial raw materials. Estimates of these flow demand shocks can be recovered from structural oil market models such as the models used in Kilian and Murphy (2013) or Kilian and Lee (2013). This approach allows us to separate the component of the real price of corn, wheat, soybeans and rice that is associated with unexpected global business-cycle fluctuations from the component that is driven by idiosyncratic shocks. Given that the global business cycle as measured in these studies relates to industrial activity, there is no reason to expect the effect of flow demand shocks on the real price of crops to be as large as their effect on the real price of oil or on other industrial commodity prices. Moreover, one would expect changes in income and in food consumption in emerging Asia to follow fluctuations in industrial activity only with a delay.

We assess this question by fitting a distributed lag model with intercept $\alpha$ to the percent change in the real price of corn:

$$
\Delta p_{t}^{\text {corn }}=\alpha+\beta_{0} u_{t}+\beta_{1} u_{t-1}+\ldots+\beta_{12} u_{t-12}+\varepsilon_{t},
$$

where the mean zero regression error $\varepsilon_{t}$ may be heteroskedastic and serially correlated, and where the regressor $u_{t}$ denotes the flow demand shock implied by an updated estimate of the structural oil market model in Kilian and Lee (2013). In estimating the distributed lag model, we 
restrict the sample to the period since May 2006 to allow for a structural change in May 2006 in the relationship between flow demand shocks and real crop prices. The response of the real price of corn to a flow demand shock may be constructed by cumulating $\partial \Delta p_{t+h}^{\text {corn }} \partial u_{t} /=\beta_{h}$, $h=0,1,2, \ldots, 12$. Similar regressions are fit for the real prices of wheat, soybeans and rice.

Figure 24 shows that all four real crop prices respond positively to a global flow demand shock, but only the responses of the real prices of corn, soybeans and rice are statistically significant based on pointwise one-standard error bands obtained using the block bootstrap. Given the short sample, this low level of statistical significance is expected.

\subsection{How Much of the Crop Price Changes Is Accounted for by the Global Business Cycle?}

Having established a tentative link between the global business cycle and real grain prices, it is natural to ask how much of the evolution of real grain prices on the basis of these estimates can be attributed to flow demand shocks. It can be shown that the explanatory power of flow demand shocks for real crop prices is far from dominant, but not negligible. The fitted values of the distributed lag regressions imply that $17 \%$ of the variation in the growth rate of the real price of wheat is explained by flow demand shocks, $19 \%$ of the variation in the growth rate of the real price of soybeans, $27 \%$ of the variation in the growth rate of the real price of corn and $24 \%$ of the variation in the growth rate of the real price of rice.

Figure 25 plots the component of these growth rates that is not explained by global flow demand shocks. Much has been made of the possibility of speculation driving agricultural crop markets. If the residual variation in Figure 25 reflected speculation in agricultural crop markets, we would expect real price changes to be highly correlated across different crops. Table 2 shows that the residual growth rates of the real prices of corn and wheat have a correlation of only 0.50 . The correlation of 0.61 between corn and soybeans is only slightly higher, whereas the 
correlation between wheat and soybeans is much lower, with an estimate of $0.40 .{ }^{15}$ These estimates cast doubt on explanations of the residual variation in the data based on speculation in agricultural crops. This impression is reinforced by inspection of Figure 25. For example, the increases in the real price of wheat in 2007 are not mirrored by similar increases in the real price of corn or soybeans, suggesting an idiosyncratic supply or demand shock in the wheat market in 2007 and 2008 (including domestic supply shocks as well as fluctuations in foreign demand for U.S. crops and in foreign supplies of crops competing with U.S. crops).

There are many other potential reasons for the residual co-movement in Table 2. Apart from droughts or floods that may affect more than one crop simultaneously, another possible explanation of a positive residual correlation would be competition for land and water in response to U.S. biofuel policies, amplified by the use of both corn and soybeans as biofuels. The latter conjecture is consistent with the higher correlation of corn with soybeans, which is also used in the production of biofuel, compared with wheat, which by and large is not. It is also consistent with a substantial increase in the residual correlations between corn and wheat and between wheat and soybeans compared with the pre-May 2006 data. It is inconsistent, however, with a largely unchanged residual correlation between corn and soybeans, compared with the pre-May 2006 data. The most striking feature of Table 2 is the low residual correlations of rice with respect to the other food commodities. In fact, these correlations are even lower than prior to May 2006, suggesting that the causes of increases in the real price of rice are unrelated to those underlying the real price of corn, soybeans and wheat.

We conclude that, after controlling for the global business cycle, none of the standard explanations provided in the policy debate, including the shift in biofuel policies, provides a good fit for the agricultural crop price data. In particular, one cannot attribute the higher

\footnotetext{
${ }^{15}$ This pattern is consistent with the fact that, in many U.S. states, soybeans and corn are substitutes in production.
} 
variability in the real price of corn, wheat and soybeans simply to biofuel mandates. Poor harvests driven by weather shocks and the evolution of the global business cycle, among other factors, also played their part. This conclusion is all the more true for the real price of rice, which is perhaps the single most important food commodity for many developing countries. There is little doubt that increases in the real price of rice were unrelated to U.S. biofuel policies and to events specific to the oil market. Figure 26 illustrates this point without the help of a formal model. It shows that the real price of rice continued to increase even as the real price of oil collapsed in the second half of 2008, and that the real price of rice declined in 2009 and 2010 while the real price of oil recovered. Moreover, the persistent decline in the real price of oil after 2009 underscores that the persistent shift in U.S. biofuel policies had no relevance for the evolution of the real price of rice, which rather appears to be due to a combination of idiosyncratic factors and a shift in global incomes. This finding is not surprising, since there is no competition between rice and corn in production.

\subsection{Implications for Developing Countries}

It may seem that the precise cause of higher agricultural crop prices is secondary when these price increases are viewed from the perspective of a developing country without a significant industrial sector. After all, the main policy concern is what higher crop prices mean for the poor in developing countries, who spend a large fraction of their income on food. Even if we accept this view, however, the causes of higher food prices matter for the design of appropriate policy responses. There also are other reasons to be cautious about accepting the usual presumption in the policy debate that higher global crop prices are responsible for political strife, malnutrition and food riots in poor countries. 
One reason is that the U.S. dollar has been fluctuating with respect to many foreign currencies, so the real price of food in the consumption units of developing countries may be much lower or much higher than the real price in U.S. consumption units. For example, the Central African Currency Unit appreciated against the U.S. dollar by nearly 20\% from mid-2006 to mid-2008, during the surge in global wheat and rice prices, presumably offsetting some of the real price increase measured in domestic consumption units. At the same time, food riots in poor countries that are usually attributed to higher crop import prices may also be associated with rapidly depreciating local currencies unrelated to agricultural markets. For example, between May 2006 and 2013, the U.S. dollar appreciated by 40\% relative to the currency of Uganda and by $50 \%$ relative to the currency of Botswana, amplifying the impact of higher international crop prices.

Another reason is that higher crop prices may be bad news for urban consumers in developing countries, but tend to be good news for farmers in rural areas. It is by no means selfevident from a welfare point of view whether developing countries overall are worse off or better off as a result of higher crop prices. Ivanic and Martin (2008) emphasize that the overall impact on poverty in developing countries depends on whether the gains to poor net food producers in rural areas outweigh the losses incurred by poor urban consumers. Answering this question requires detailed household survey data. Whether higher food commodity prices improve or worsen the welfare of a particular household depends on the products involved, how integrated the poor are into the cash economy, their pattern of incomes and expenditures, other economic changes potentially associated with higher commodity food prices (such as higher real wages for unskilled labor in the context of a booming economy), and, most importantly, the domestic and trade policies pursued by the governments in poor countries. In related work, Ivanic, Martin and 
Zaman (2012) conclude that the 2010-11 increase in food commodity prices was associated with approximately a $1 \%$ increase in poverty in low-income countries, on average, with enormous variation across countries. The statistical significance of this estimate is not assessed, however.

It is indeed ironic that, for decades, declining real prices of crops have been held responsible for the economic plight of many developing countries, but now a reversal of this trend is considered equally detrimental to their welfare. Undoubtedly, an important determinant of the effects of higher food commodity prices on the poor in low-income countries is government policies. Ivanic and Martin's (2008) empirical analysis confirms that an increase in the real price of rice, for example, raises welfare in countries such as Vietnam, given the relatively egalitarian land distribution in that country, while it lowers welfare in countries such as Pakistan, with a higher fraction of poor urban consumers. This evidence suggests that we need to be careful not to attribute the effects of long-standing government policies to higher food commodity prices. Given that, in some developing countries, mismanagement and government restrictions have stunted the agricultural sector to the point that food imports are the only option available to the government to pacify the urban poor, it seems especially misleading to hold higher global crop prices responsible for the effects of these countries' earlier government interventions.

Nor does it seem warranted to view higher price volatility in food commodity markets as exogenous with respect to poor countries. Martin and Anderson (2011), for example, stress that trade barriers intended to shield poor countries from fluctuations in food commodity prices may in fact have magnified the international price instability associated with exogenous shocks. They estimate that $45 \%$ of the increase in the global price of rice and $30 \%$ of the increase in the global price of wheat during 2005-08 can be explained by changes in border protection rates. In fact, 
Anderson, Ivanic and Martin (2013) conclude that the net effect of policies intended to insulate poor consumers from food commodity price shocks on global markets may actually have increased global poverty in 2008 .

Finally, one must not forget that it is in part the economic success of emerging economies that has contributed to a substantial increase in oil prices as well as agricultural crop prices in the first place. Surely, we would not want to deny developing countries pursuing sensible economic policies the right to industrialize just because other developing countries pursuing harmful economic policies have a hard time coping with higher food import prices as a result. A more sensible policy approach would be to insist that all developing countries with food shortages, including countries in Africa and in the Middle East, implement economic policies that facilitate the development of their agricultural sector if they find themselves unable to pay for food imports. A good case can be made that inappropriate policies are the primary cause of the observed food shortages.

None of these caveats diminish the economic plight of the urban and rural poor in many developing countries, and the fact that higher food commodity prices may worsen their economic situation, but the caveats do suggest that a more nuanced view than the testimony of Rosegrant (2008), for example, is important in developing policy solutions to these problems.

\section{Conclusion}

There is substantial evidence that U.S. biofuel policies have been associated with sizable increases in the real price of corn since 2006, as the production of ethanol began to compete for the production of food. In this paper, we examined the complementary question of the transmission of oil price shocks to food prices both prior to and after this change in U.S. policy. One concern is the extent to which higher oil prices cause higher food prices. A related concern 
is how this transmission takes place in practice. These questions have taken on a new importance, as policy-makers are growing increasingly concerned about the prospects of a global food shortage.

A common perception among academics and policy-makers is that oil price increases in recent years have been associated with higher food prices. Some pundits have gone so far as to assert that food prices mirror oil prices. We have shown that there is no evidence that retail food prices closely track oil prices before or after the change in U.S. biofuel policies in May 2006. Notwithstanding substantial variation in the real price of crude oil, indices of the real retail price of food faced by U.S. consumers remained remarkably stable over time, even after the shift in U.S. biofuel policies. This is not true, however, for the real price of major agricultural commodities produced in the United States, such as corn, wheat, soybeans and rice. Corn and soybeans experienced average real price increases of between $12 \%$ and $15 \%$ per year after May 2006 , while the real prices of wheat and rice grew at an annual rate of $7 \%$.

The distinction between retail food prices and the prices received by farmers for grain crops and livestock is important. Policy concerns about a looming food shortage to date appear to be based on rising real crop prices received by farmers, as opposed to rising real food prices faced by U.S. consumers. Although U.S. consumer food prices have increased substantially in nominal terms, the cost of food measured in terms of other consumer goods has increased only by $7 \%$ cumulatively since May 2006 (or 1\% per year). The discrepancy between the slow growth in real consumer food prices and the more rapid growth in the crop prices received by farmers is explained by the small producer share in the food prices paid by U.S. consumers. For example, the farm value of wheat in the price of bread is only about $5 \%$, so even substantial wheat price increases are associated with only small increases in the price of bread. 
With regard to the question of how much one would expect agricultural and food prices to increase in response to a one-time unexpected increase in the real price of crude oil, we showed that, after May 2006, unexpected increases in the real price of oil have indeed been followed by systematic increases in some U.S. crop prices. For example, a 1\% real oil price shock tends to be followed by a persistent and statistically significant increase in the real price of corn that peaks at $0.5 \%$ one year later. There also is evidence that, after May 2006, these same real oil price shocks have been followed by increases in U.S. consumer prices for food relative to the CPI excluding food and energy, but the latter increases are very small by comparison. The peak response is only $0.05 \%$.

We emphasized that these effects should not be interpreted as the causal effects of higher oil prices, however, because the real oil price shocks since May 2006 mainly reflected broadbased shifts in the demand for industrial and agricultural commodities. We showed, for example, that even the real price of fertilizer (which does not depend on the price of crude oil but on the price of natural gas) appears to respond to real oil price shocks. Given the divergence of the prices of oil and natural gas in recent years, this evidence can only be explained by a common shift in the demand for crude oil and for agricultural products. Indeed, $27 \%$ of the variation in the growth rate of the real price of corn since May 2006, for example, is explained based on unexpected changes in demand associated with shifts in global industrial activity. We stressed that the remaining variation is by no means explained simply based on corn-ethanol mandates. Our analysis suggests that a combination of government policies, idiosyncratic harvest shocks and idiosyncratic demand shocks is required to explain the residual variation in the crop price data, along with the fact that higher oil prices made ethanol more cost competitive. In other 
words, there is no simple explanation for the evolution of the real prices of corn, wheat, soybeans and rice.

With regard to the question of how much of the observed response of retail food prices is associated with higher crop prices, and how much reflects the costs of processing and delivering these crops to the consumer, we found that, contrary to prevailing wisdom, there is no evidence that unexpected increases in the real price of oil are associated with higher food prices because of the increased cost of processing, transporting and distributing food. To the extent that there is any pass-through from oil to food prices, it reflects higher crop prices only.

These results are in striking contrast with a growing literature and public debate on the emergence of global food shortages. It has been common in this debate simply to equate food prices with the prices of key agricultural commodities such as wheat, corn, soybeans and rice. We have shown, first, that care must be exercised in drawing a distinction between the prices of agricultural products and the retail price of food. Second, much of the policy debate in question has centered on the premise of increased food price volatility in recent years. It has been common to attribute hunger and malnutrition among the poor to this food price volatility. Our analysis has shown that there has been no systematically increased food price volatility. Only for wheat is there any evidence of a noticeable increase in price volatility, and the reasons appear to be idiosyncratic rather than systematic. Moreover, we stressed that the real problem for food consumers, if there is one, is one of rising prices, not of volatile prices. In this sense, the concern among policy-makers about price volatility seems misplaced.

Given the absence of large spikes or surges in U.S. retail food prices, there is no evidence that rising food prices have had major welfare implications in the United States. We would expect similar results for other industrialized economies (and, increasingly, for emerging 
economies), in which food consumption relies heavily on processed foods. A different question is the extent to which increases in the real price of food commodities affect the welfare of poor people in the least-industrialized countries, who tend to consume less processed food and spend a larger share of their income on food. The answer is not obvious, because poor farmers in developing countries are likely to be producers as well as consumers of food commodities. Providing a reliable answer to this question requires detailed household survey data for extended periods. Recent studies show enormous variation in the effects of higher food commodity prices on poverty in developing economies. Our interpretation of this evidence is that, whether a country benefits from rising food commodity prices or not, an important part appears related to the agricultural, exchange rate and trade policies it pursues, and that these policies tend to predate recent food commodity price increases. We made the case that a more nuanced analysis is called for in developing policy proposals to deal with these problems than is embodied in many current policy documents. 


\section{References}

Abbott, P. (2013), "Biofuels, Binding Constraints, and Agricultural Commodity Price Volatility," forthcoming in: The Economics of Food Price Volatility, National Bureau of Economic Research, University of Chicago Press.

Anderson, S.T., and A. Elzinga (2013), “A Ban on One is a Boon for the Other: Strict Gasoline Content Rules and Implicit Ethanol Blending Mandates,” mimeo, Michigan State University.

Anderson, K., Ivanic, M., and W. Martin (2013), "Food Price Spikes, Price Insulation, and Poverty," forthcoming in: The Economics of Food Price Volatility, National Bureau of Economic Research, University of Chicago Press.

Babcock, B.A. (2013), "Ethanol without Subsidies: An Oxymoron or the New Reality?" forthcoming: American Journal of Agricultural Economics.

Baumeister, C., Kilian, L., and X. Zhou (2013), “Are Product Spreads Useful for Forecasting? An Empirical Evaluation of the Verleger Hypothesis," Bank of Canada Working Paper No. 2013-25.

Berck, P., Leibtag, E., Solis, A., and S. Villas-Boas (2009), “Patterns of Pass-Through of Commodity Price Shocks to Retail Prices," American Journal of Agricultural Economics, 91, 1456-1461.

Bruno, V.G., Büyükşahin, B., and M.A. Robe (2013), “The Financialization of Food?” Bank of Canada Working Paper No. 2013-39.

Carter, C., Rausser, G., and A. Smith (2013), "Commodity Storage and the Market Effects of Biofuel Policies," mimeo, UC Davis.

Chavas, J.-P., Hummels, D., and B.D. Wright (2013), "Introduction to 'Economics and Food 
Price Volatility'," forthcoming in: The Economics of Food Price Volatility, National Bureau of Economic Research, University of Chicago Press.

Dancy, J. (2012), “Food Prices Mirror Oil Prices: The Crude Oil-FAO Food Price Index Price Correlation," Financial Sense, May 14.

Edelstein, P., and L. Kilian (2009), "How Sensitive Are Consumer Expenditures to Retail Energy Prices?” Journal of Monetary Economics, 56, 766-779.

Elliott, G. (1998), “On the Robustness of Cointegration Methods when Regressors Almost Have Unit Roots," Econometrica, 66, 149-158.

Fattouh, B., Kilian, L., and L. Mahadeva (2013), "The Role of Speculation in Oil Markets: What Have We Learned So Far?” Energy Journal, 34, 7-33.

Goncalves, S., and L. Kilian (2004), "Bootstrapping Autoregressions in the Presence of Conditional Heteroskedasticity of Unknown Form," Journal of Econometrics, 123, 89120.

Gospodinov, N., Herrera, A.M. and E. Pesavento (2013), "Unit Roots, Cointegration and PreTesting in VAR Models," forthcoming: Advances in Econometrics.

Hamilton, J.D. (2012), “Import Prices and Inflation,” International Journal of Central Banking, $8,271-279$.

Hausman, C., Auffhammer, M., and P. Berck (2012), "Farm Acreage Shocks and Crop Prices: An SVAR Approach to Understanding the Impacts of Biofuels," Environmental and Resource Economics, 53, 117-136.

Inman, P. (2011), “Food Price Rises Pushing Millions into Extreme Poverty, World Bank Warns," The Guardian, April 14.

Inoue, A., and L. Kilian (2002), "Bootstrapping Autoregressive Processes with Possible Unit 
Roots," Econometrica, 70, 377-391.

Interagency Report to the G20 (2011), Price Volatility in Food and Agricultural Markets: Policy

Responses. Policy report including contributions by FAO, IFAD, IMF, OECD,

UNCTAD, WFP, World Bank, WTO, IFPRI, and UN HLTF.

Ivanic, M., and W. Martin (2008), "Implications of Higher Global Food Prices for Poverty in Low-Income Countries,” Policy Research Working Paper No. 4594, World Bank.

Ivanic, M., Martin, W., and H. Zaman (2012), "Estimating the Short-Run Poverty Impacts of the 2010-11 Surge in Food Prices," World Development, 40, 2302-2317.

Janzen, J.P., Carter, C.A., Smith, A.D., and M.K. Adjemian (2013), “Deconstructing Wheat Price Spikes: A Model of Supply and Demand, Financial Speculation, and Commodity Price Co-movement,” U.S.D.A. Economic Research Report.

Kilian, L. (2008a), "Exogenous Oil Supply Shocks: How Big Are They and How Much Do They Matter for the U.S. Economy?" Review of Economics and Statistics, 90, 216-240.

Kilian, L. (2008b), “The Economic Effects of Energy Price Shocks," Journal of Economic Literature, 46, 871-909.

Kilian, L. (2010), "Explaining Fluctuations in U.S. Gasoline Prices: A Joint Model of the Global Crude Oil Market and the U.S. Retail Gasoline Market,” Energy Journal, 31, 87-104.

Kilian, L., and B. Hicks (2013), "Did Unexpectedly Strong Economic Growth Cause the Oil Price Shock of 2003-2008?”, Journal of Forecasting, 32, 385-394.

Kilian, L., and T.K. Lee (2013), "Quantifying the Speculative Component in the Real Price of Oil: The Role of Global Oil Inventories," forthcoming: Journal of International Money and Finance.

Kilian, L., and D.P. Murphy (2013), “The Role of Inventories and Speculative Trading in the 
Global Market for Crude Oil," forthcoming: Journal of Applied Econometrics.

Kilian, L., and C. Vega (2011), "Do Energy Prices Respond to U.S. Macroeconomic News? A Test of the Hypothesis of Predetermined Energy Prices," Review of Economics and Statistics, 93(2), 660-671.

Kilian, L., and R.J. Vigfusson (2011), “Are the Responses of the U.S. Economy Asymmetric in Energy Price Increases and Decreases?" Quantitative Economics, 2, 419-453.

Leibtag, E. (2009), "How Much and How Quick? Pass Through of Commodity and Input Cost Changes to Retail Food Prices," American Journal of Agricultural Economics, 91, 14621467.

Mallory, M., Irwin, S., and D. Hayes (2012), "How Market Efficiency and the Theory of Storage Link Corn and Ethanol Markets," Energy Economics, 34, 2157-2166.

Martin, W., and K. Anderson (2011), “Export Restrictions and Price Insulation during Commodity Price Booms,” American Journal of Agricultural Economics, 94, 422-427.

McPhail, L.L. (2011), “Assessing the Impact of U.S. Ethanol on Fossil Fuel Markets: A Structural VAR Approach,” Energy Economics, 1177-1185.

Pesaran, M.H., and A. Timmermann (2009), "Testing Dependence Among Serially Correlated Multicategory Variables," Journal of the American Statistical Association, 104, 325-337.

Roberts, M.J., and W. Schlenker (2013), "Identifying Supply and Demand Elasticities of Agricultural Commodities: Implications for the U.S. Ethanol Mandate," forthcoming: American Economic Review.

Roeger, E., and E. Leibtag (2011), "How Retail Beef and Bread Prices Respond to Changes in Ingredient and Input Costs," Economic Research Report No. 112, U.S. Department of Agriculture. 
Rosegrant, M.W. (2008), "Biofuels and Grain Prices: Impacts and Policy Responses,” Testimony for the U.S. Senate Committee on Homeland Security and Governmental Affairs, May 7.

Sands, R., and P. Westcott (2011), "Impacts of Higher Energy Prices on Agriculture and Rural Economies,” Economic Research Report No. 123, U.S. Department of Agriculture.

Serra, T., and D. Zilberman (2013), "Biofuel-related Price Transmission Literature: A Review," Energy Economics, 37, 141-151.

Sims, C. A., Stock, J.H., and M. W. Watson (1990), "Inference in Linear Time Series Models with Some Unit Roots," Econometrica, 58, 113-144.

Tyner, W.E. (2010), “The Integration of Energy and Agricultural Markets,” Agricultural Economics, 41, 193-201.

Venditti, F. (2013), "From Oil to Consumer Energy Prices: How Much Asymmetry Along the Way?", forthcoming: Energy Economics.

Westhoff, P. (2012), "Oil Prices Affect the Cost of Food in Many Ways," Columbia Daily Tribune, March 3.

Wiggins, J. (2007), “Fears over Food Price Inflation,” Financial Times, London, May 23. 
Table 1: Percent Changes in Selected U.S. Prices Relative to Non-Food CPI

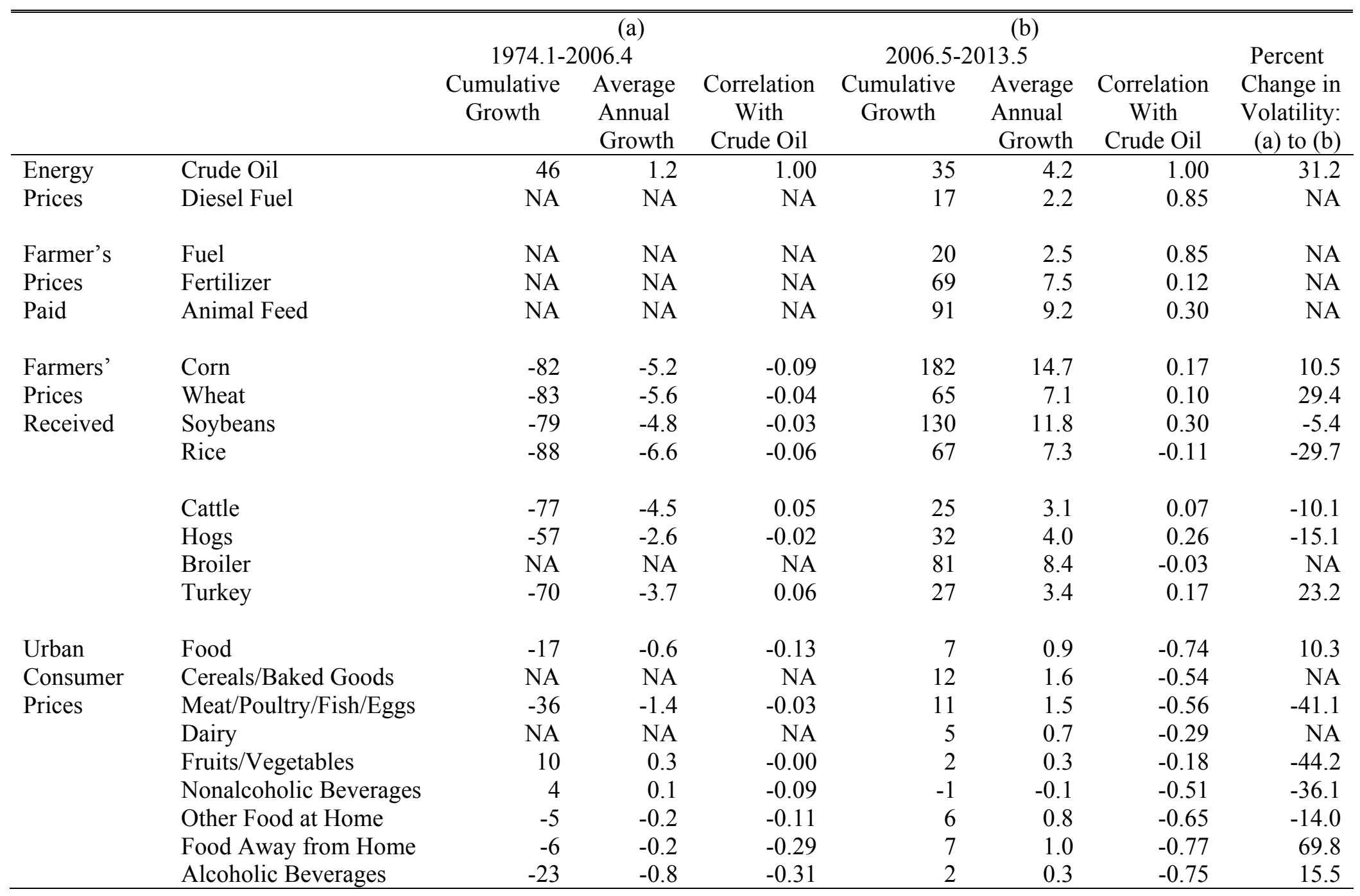

NOTES: The data are described in the appendix. NA denotes missing entries resulting from gaps in the available data. The percent change in volatility is based on the ratio of the standard deviations of the percent growth rate in the respective periods. The correlations refer to correlations between the monthly growth rates in the real price of oil and in the series of interest. 
Table 2: Correlation of Residuals Growth Rates in Real Grain Prices after Controlling for Cumulative Effect of Flow Demand Shocks 2006.5-2013.5

\begin{tabular}{ccccc}
\hline \hline & Real corn price & Real wheat price & Real soybean price & Real rice price \\
\hline Real corn price & 1 & 0.50 & 0.61 & 0.06 \\
Real wheat price & - & 1 & 0.40 & -0.04 \\
Real soybean price & - & - & 1 & 0.08 \\
Real rice price & - & - & - & 1 \\
\hline
\end{tabular}

NOTES: Authors' computations based on residuals from distributed lag models relating the growth rate in each real grain price to exogenous flow demand shocks obtained from an update of the model of Kilian and Lee (2013). 
Figure 1: Cumulative Percent Growth in U.S. Consumer Prices for Food since 2006.5

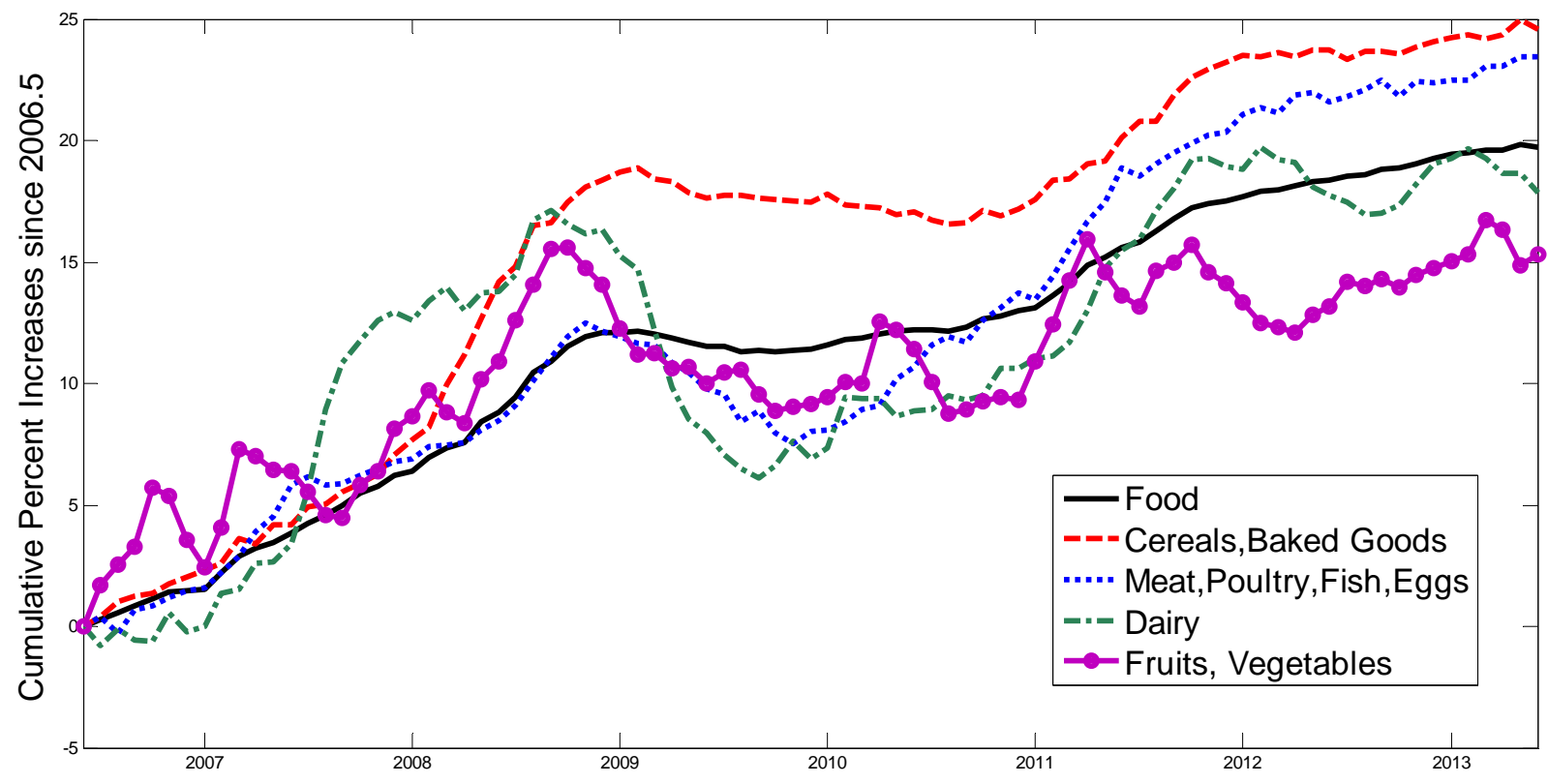

NOTES: Authors' computations based on the data described in the appendix.

Figure 2: U.S. Consumer Food Prices Relative to Non-Food Consumer Prices 2006.5-2013.5

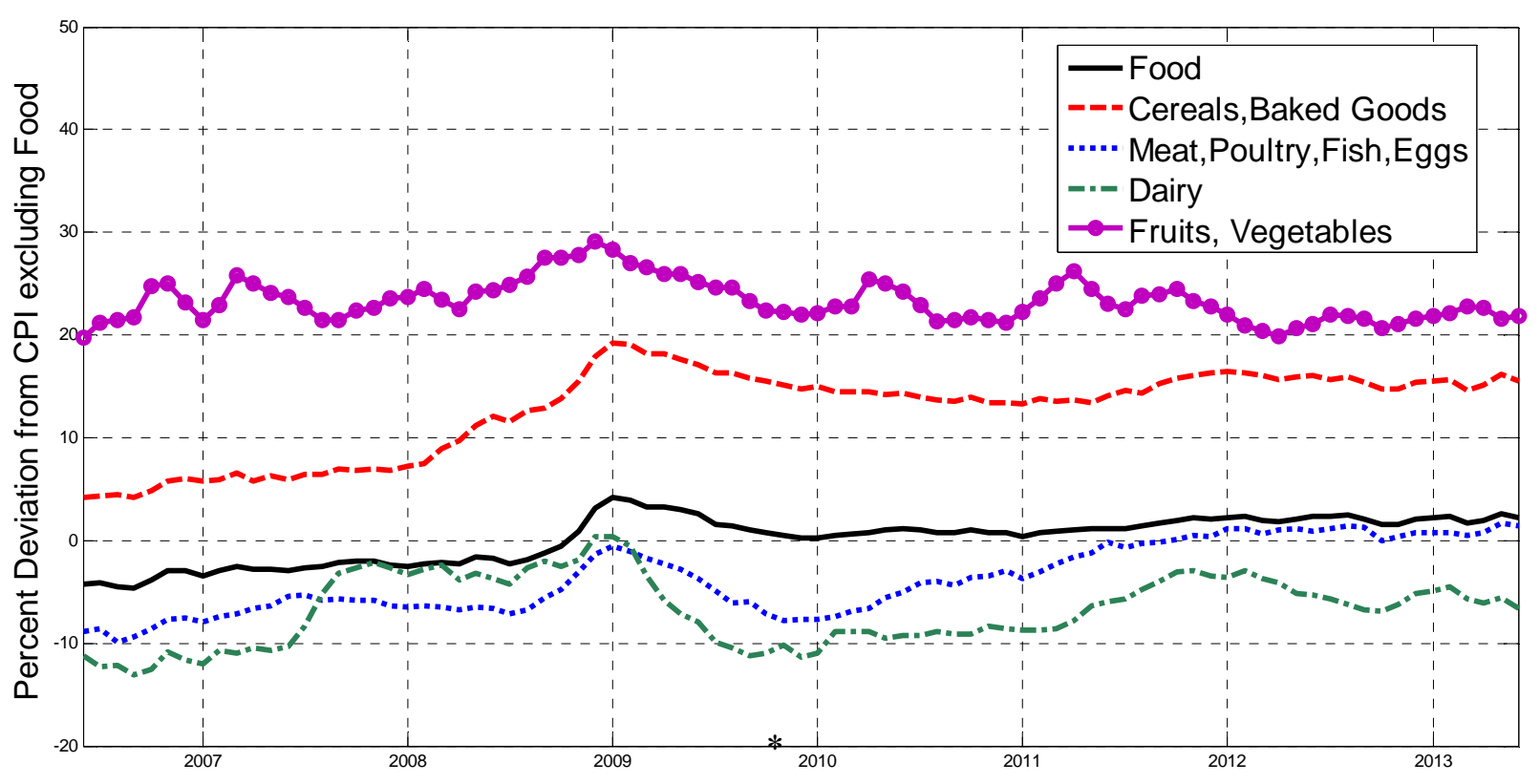

NOTES: Authors' computations based on the data described in the appendix. 
Figure 3: Price of Crude Oil and U.S. Food Consumer Price Index Relative to U.S. Non-Food CPI 1974.1-2013.5

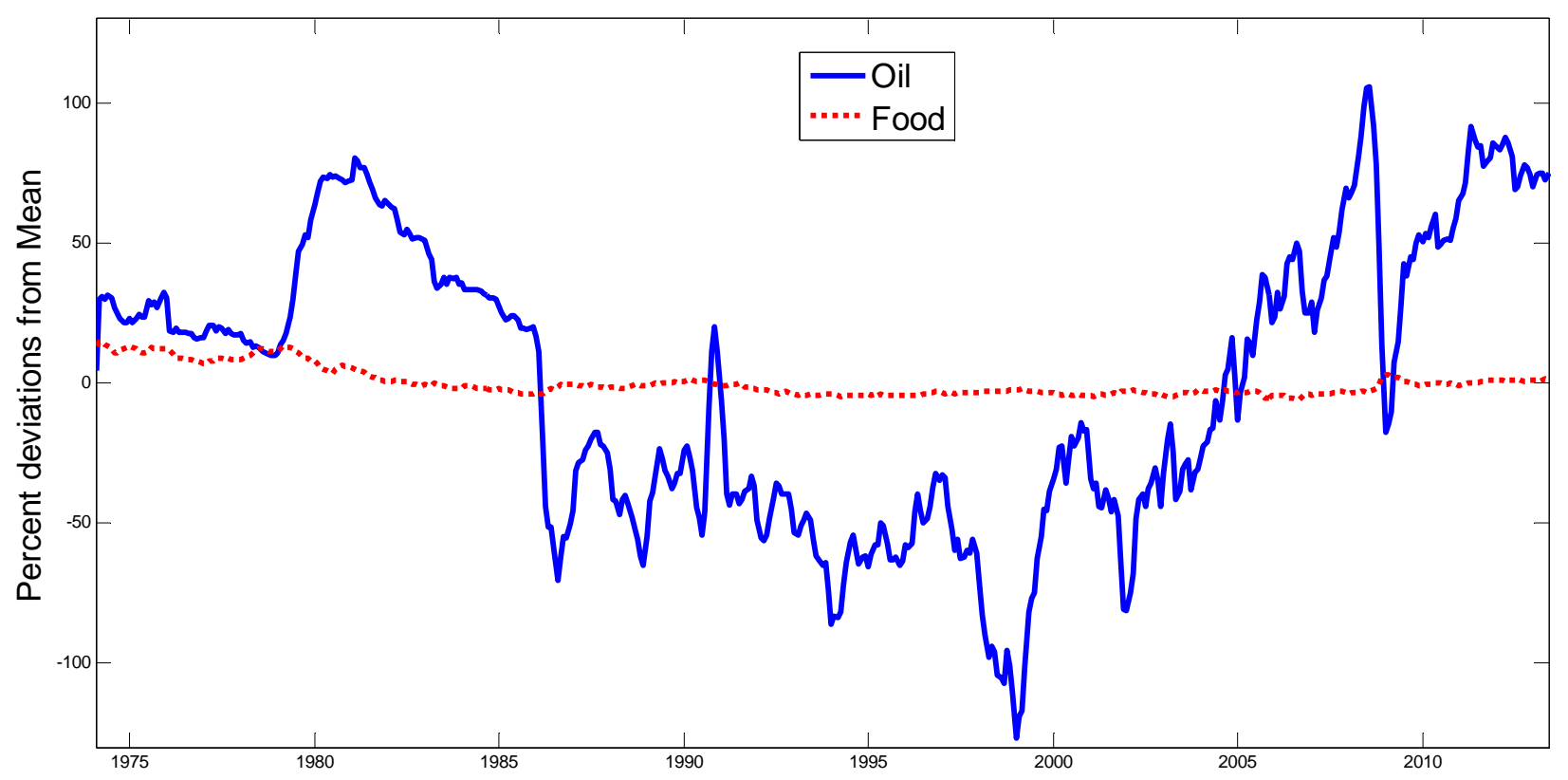

NOTES: Authors' computations based on the data described in the appendix.

Figure 4a: Real Prices Received by U.S. Farmers and Real Price of Crude Oil 1974.1-2006.4

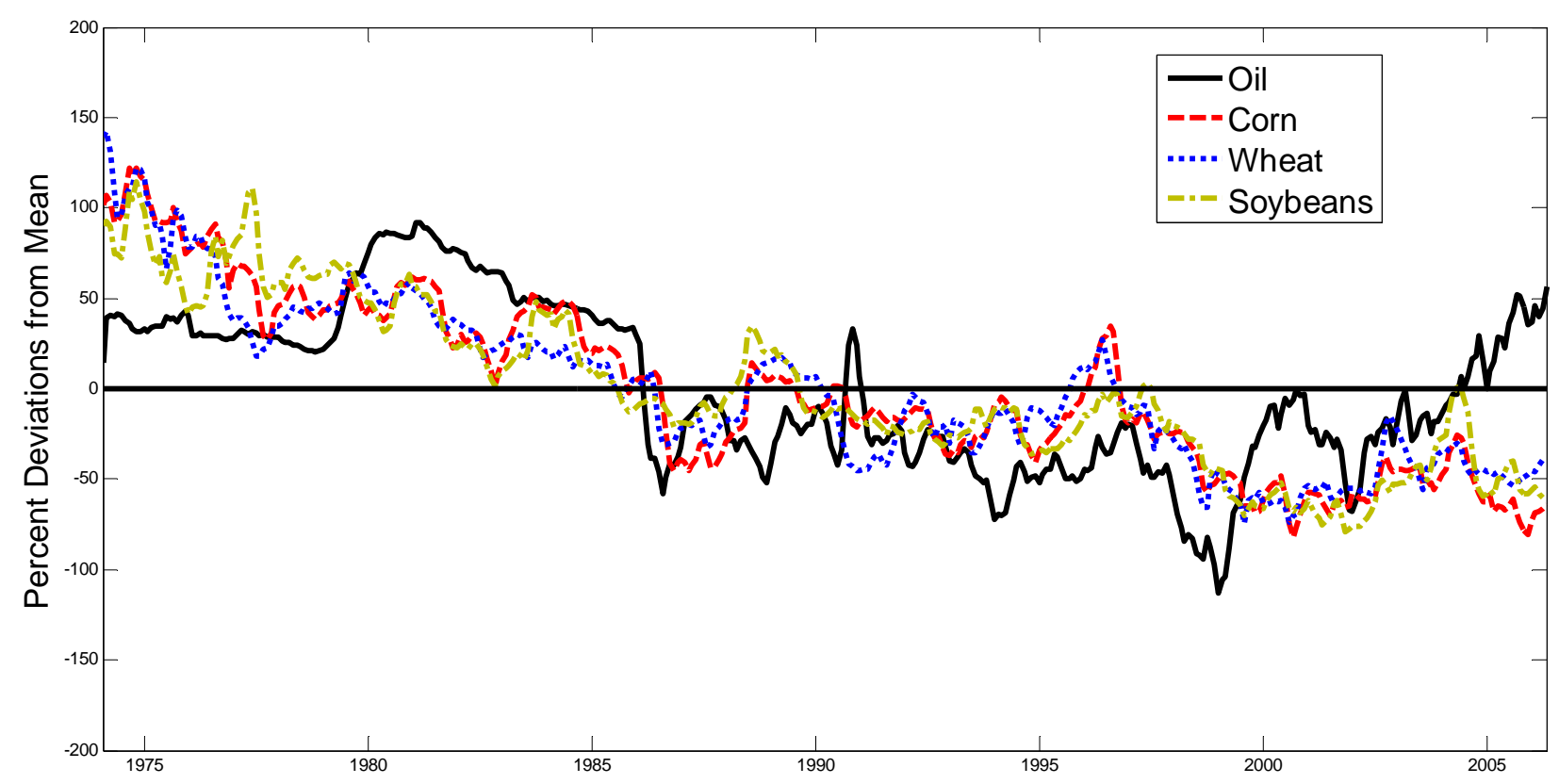

NOTES: Authors' computations based on the data described in the appendix. 
Figure 4b: Real Prices Received by U.S. Farmers and Real Price of Crude Oil 2006.5-2013.5

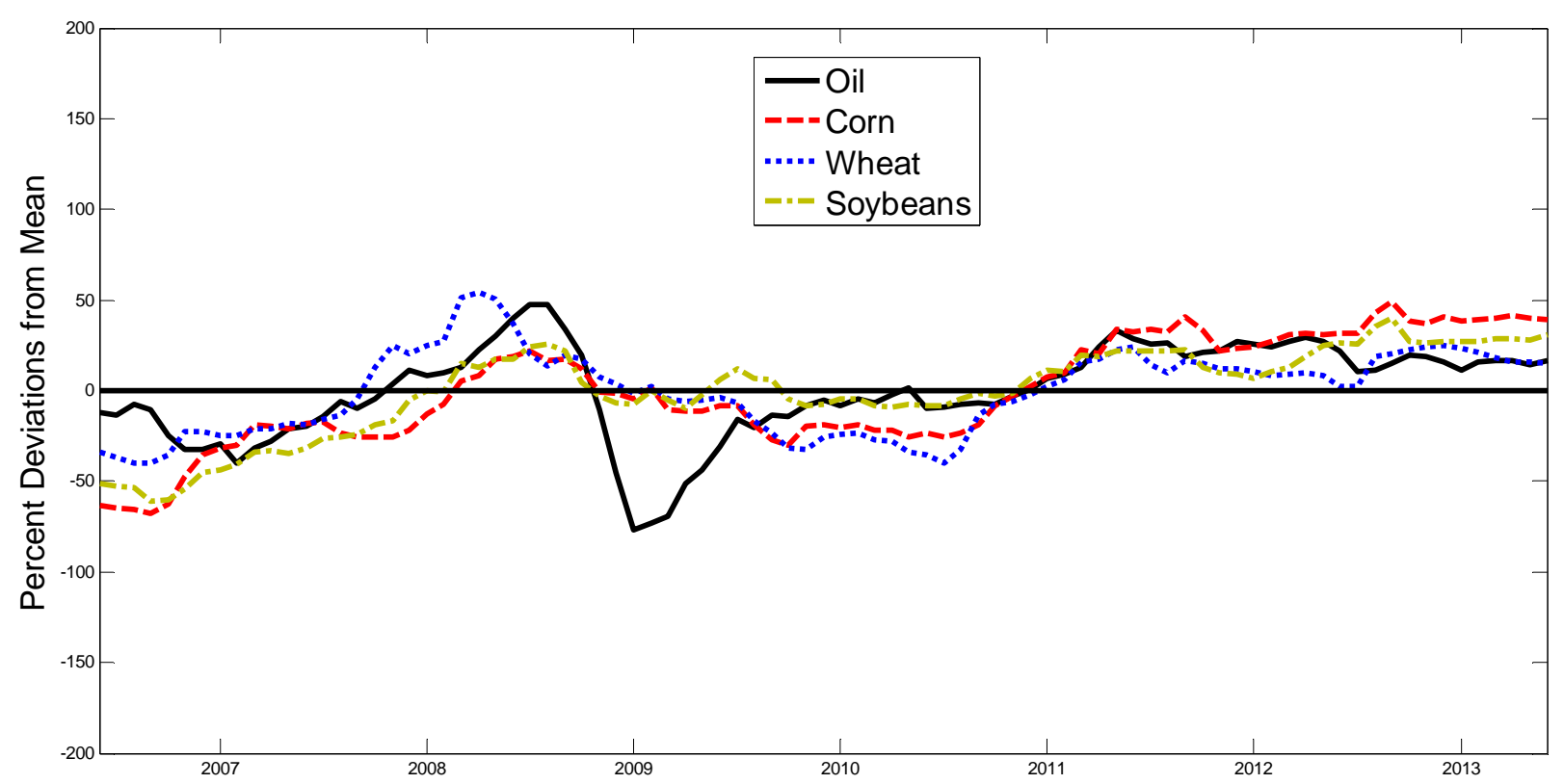

NOTES: Authors' computations based on the data described in the appendix.

Figure 5: Percent Growth Rates of Selected Prices Before and After May 2006

1999.5-2006.4

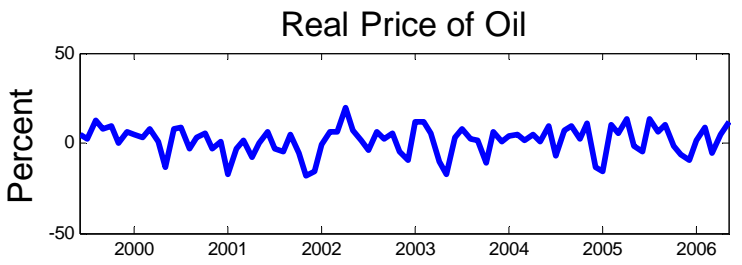

Real Price of Corn

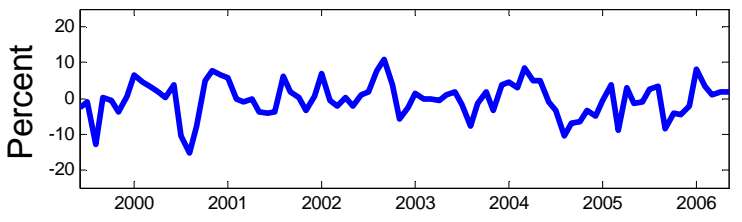

Real Price of Food

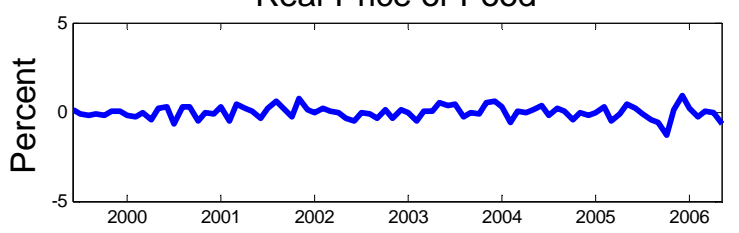

2006.6-2013.5

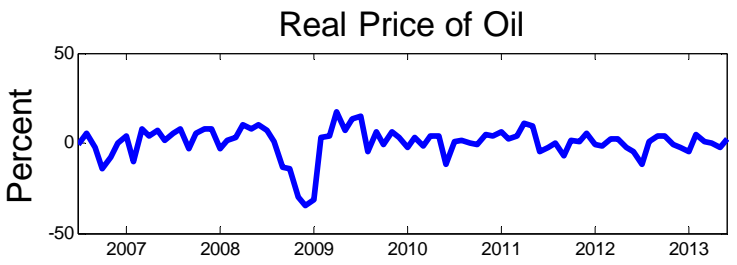

Real Price of Corn

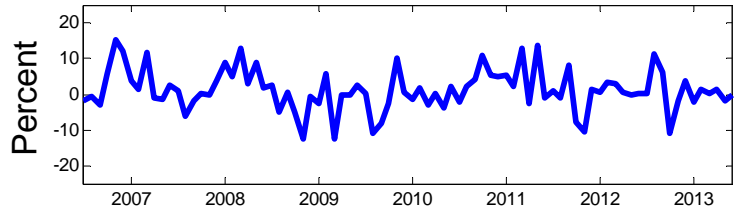

Real Price of Food

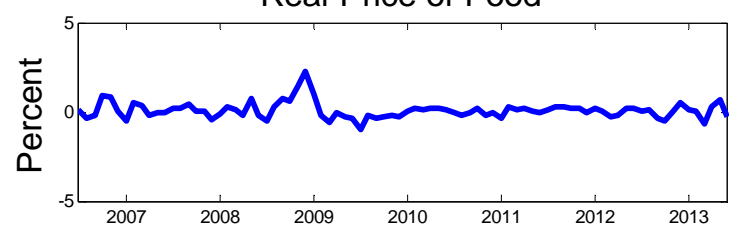

NOTES: Authors' computations based on the data described in the appendix. 
Figure 6a: Case Study of Farm Crop Prices during 1990

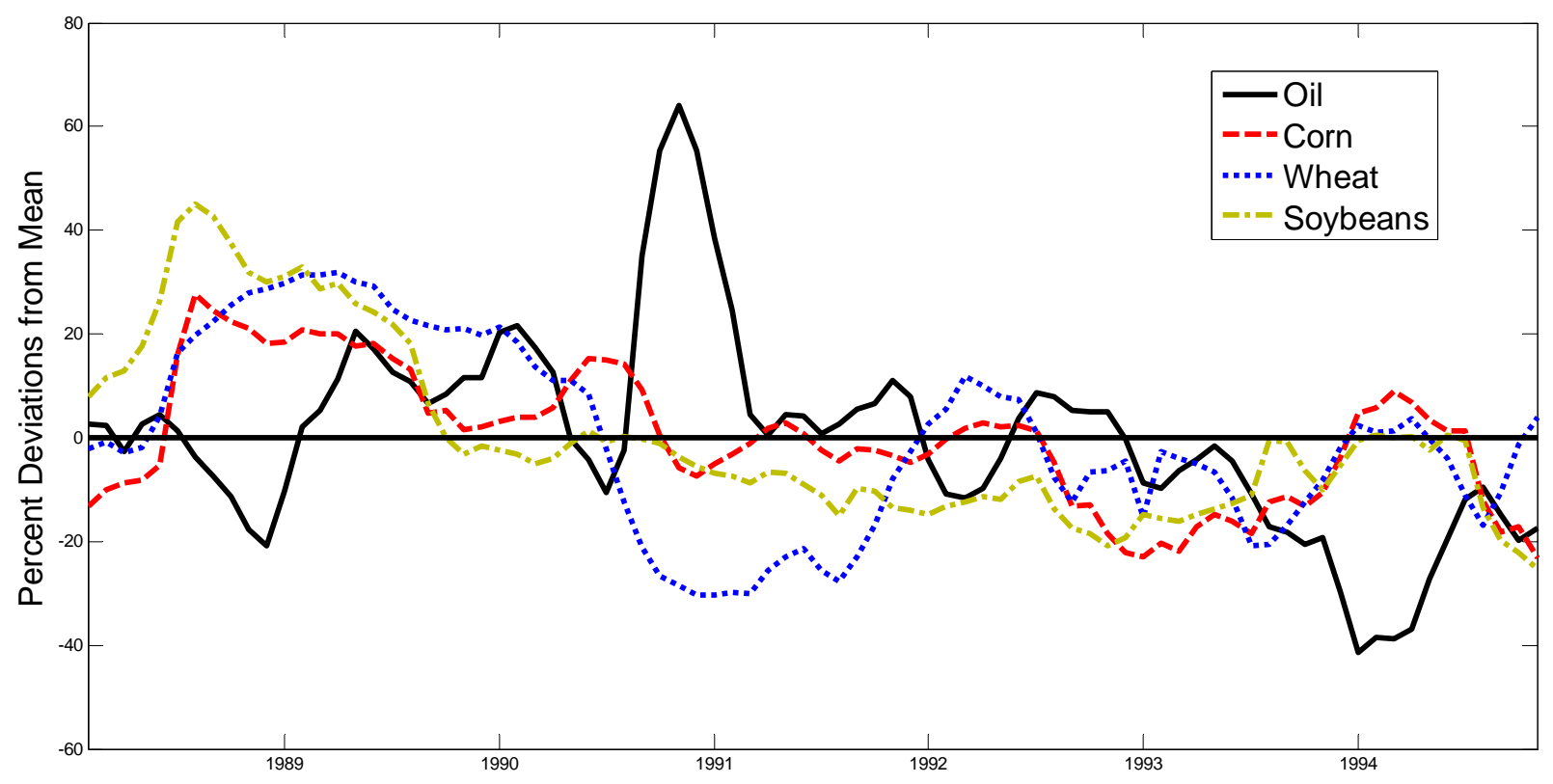

NOTES: Authors' computations based on the data described in the appendix.

Figure 6b: Case Study of Farm Input Prices during 1990

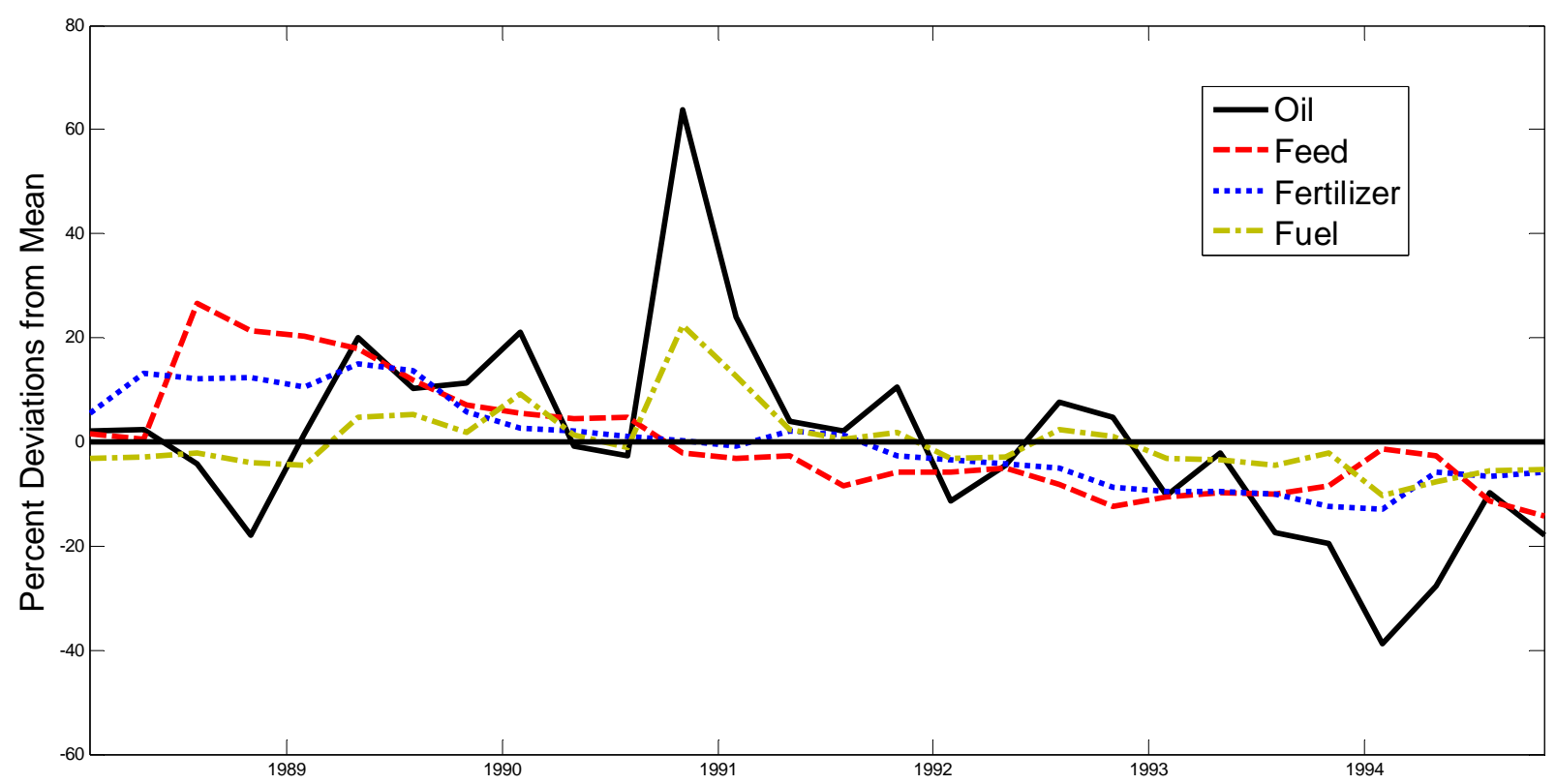

NOTES: Authors' computations based on the data described in the appendix. 
Figure 7a: Spread of Price of Oil to Price of Corn Received by U.S. Farmers 1974.1-2006.4

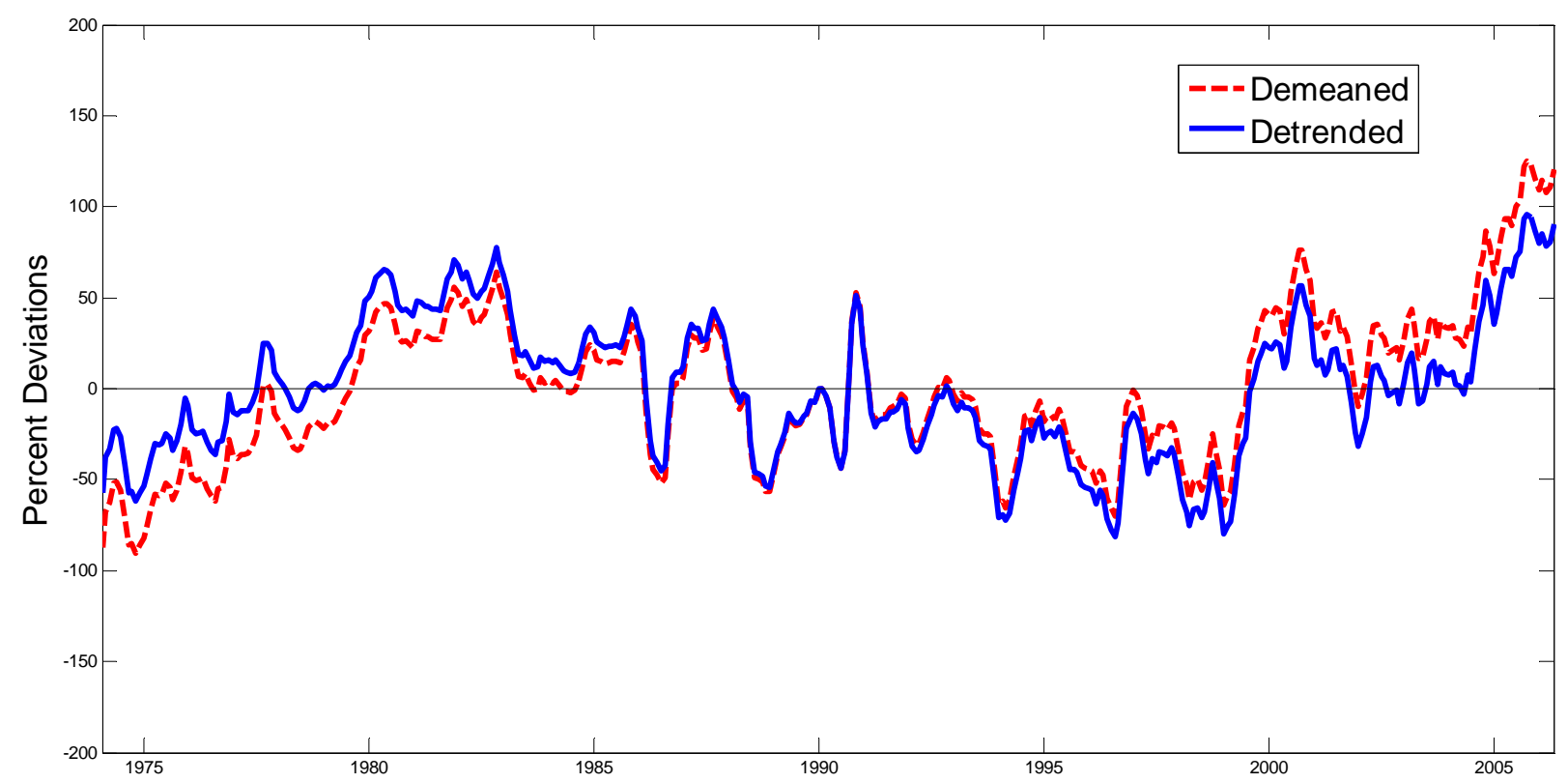

NOTES: Authors' computations based on the data described in the appendix.

Figure 7b: Spread of Price of Oil to Price of Corn Received by U.S. Farmers 2006.5-2013.5

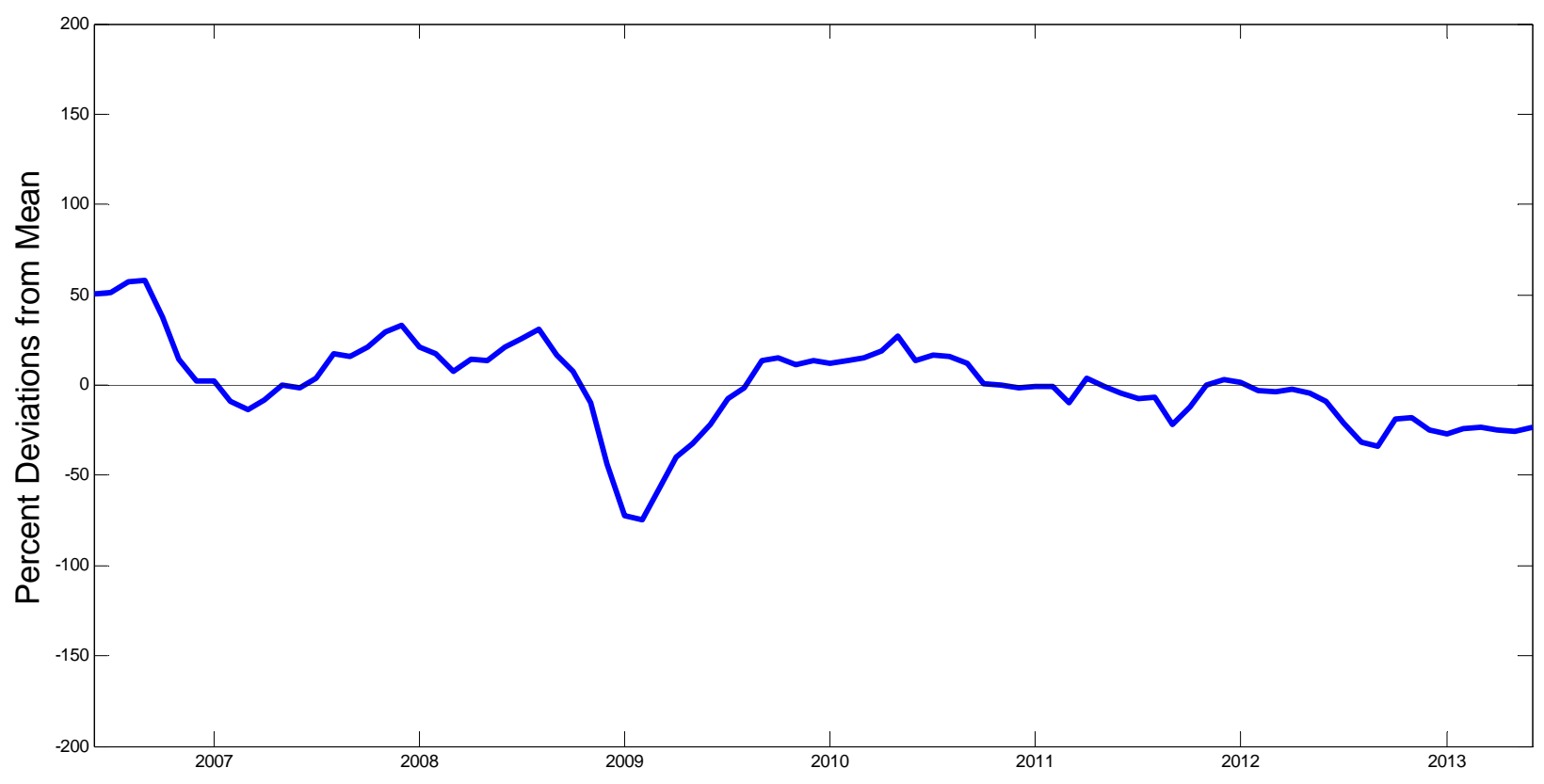

NOTES: Authors' computations based on the data described in the appendix. 
Figure 8: Real Price of Energy and Real Price of U.S. Farm Inputs
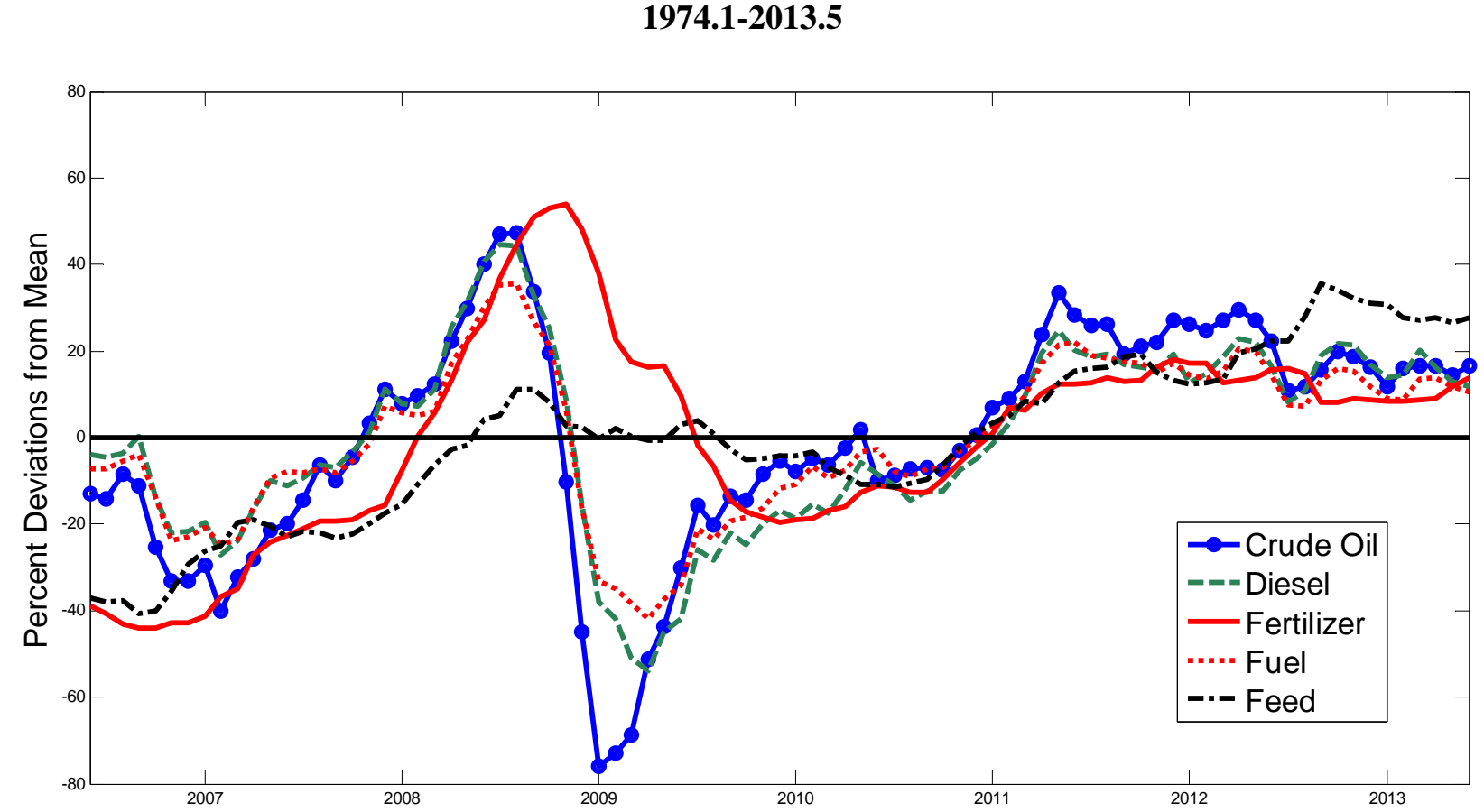

NOTES: Authors' computations based on the data described in the appendix.

Figure 9: Response to a 1\% Real Oil Price Shock Consumer Food Prices Relative to Consumer Prices Excluding Food
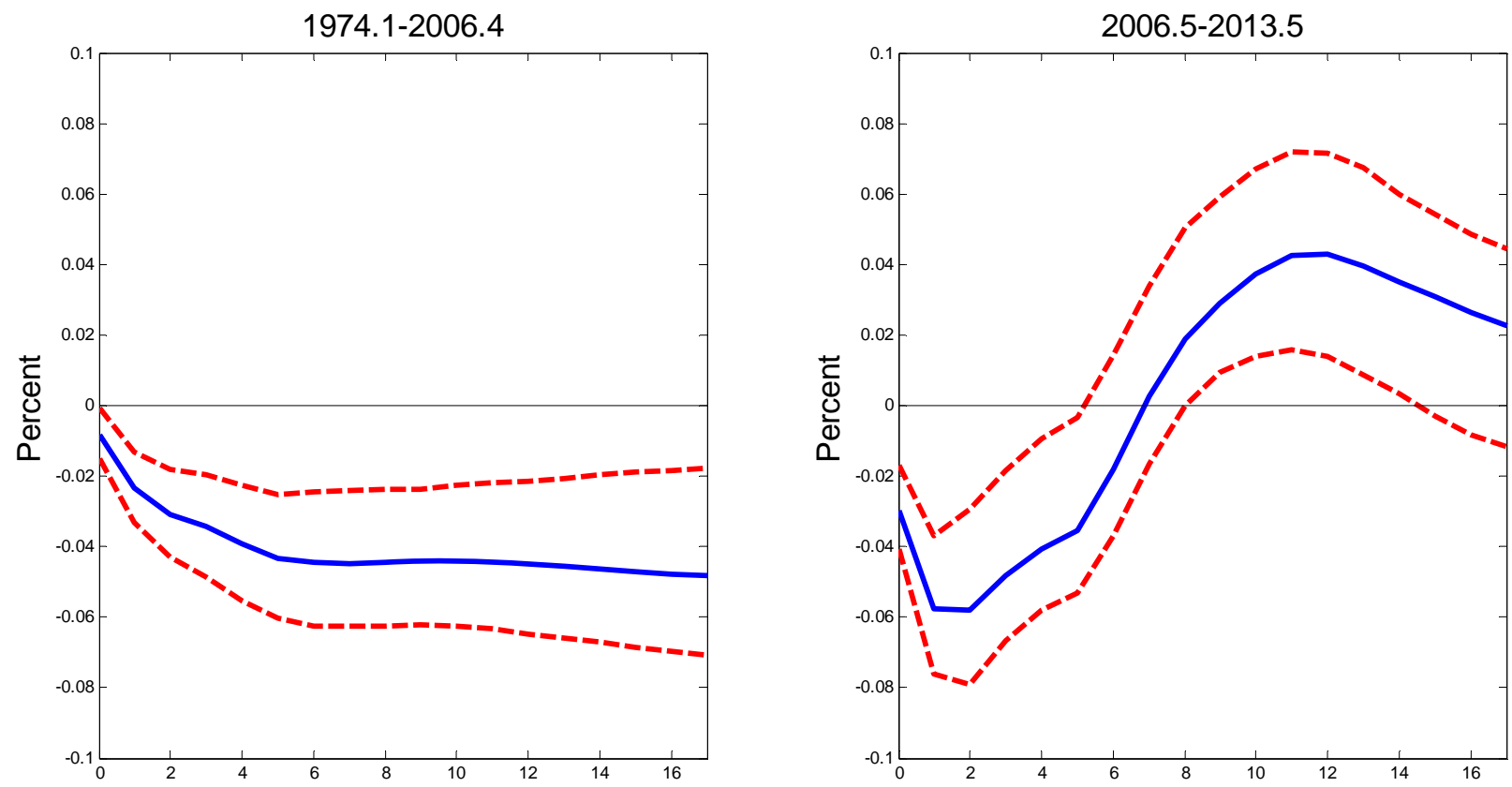

NOTES: Estimates from monthly bivariate vector autoregressions under the identifying assumption that the real price of oil is predetermined with $90 \%$ bootstrap confidence bands. 
Figure 10: Response to a 1\% Real Oil Price Shock Consumer Food Prices Relative to Consumer Prices Excluding Food and Energy
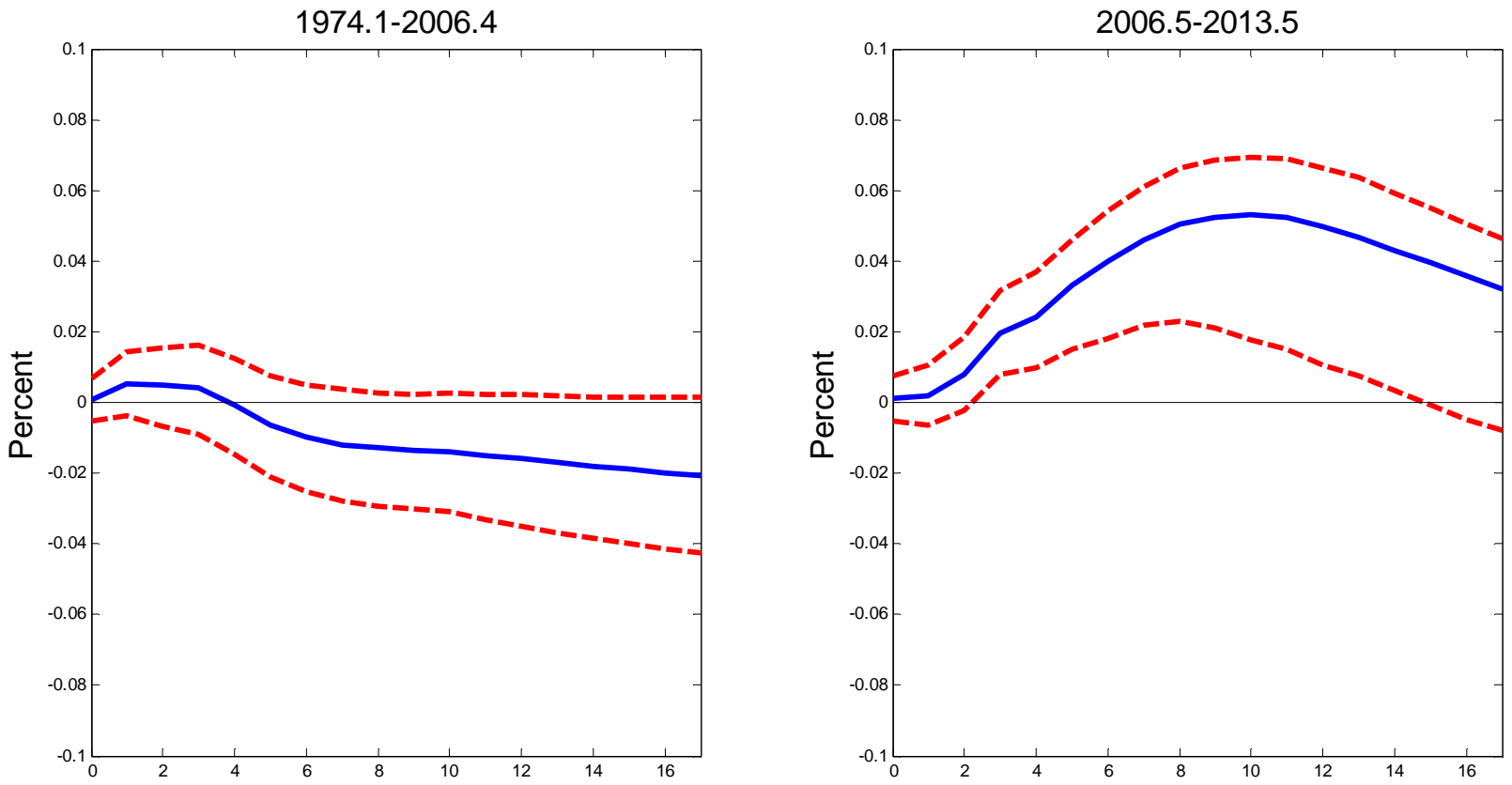

NOTES: Estimates from monthly bivariate vector autoregressions under the identifying assumption that the real price of oil is predetermined with $90 \%$ bootstrap confidence bands.

Figure 11: Response of Real Food Prices to a 1\% Real Oil Price Shock 2006.5-2013.5
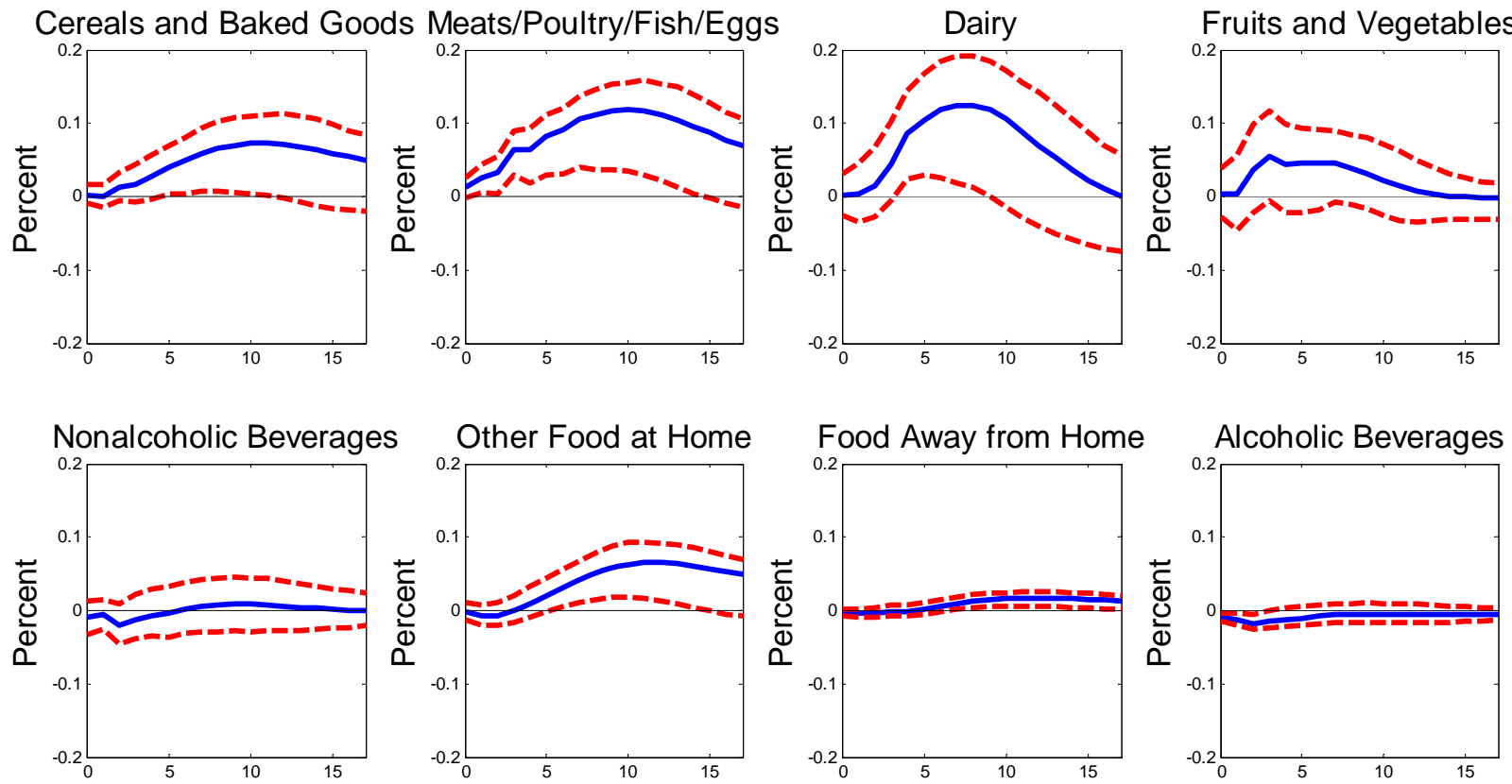

NOTES: Estimates from monthly bivariate vector autoregressions under the identifying assumption that the real price of oil is predetermined with $90 \%$ bootstrap confidence bands. 
Figure 12: Response to a 1\% Real Oil Price Shock

Corn Price Received by U.S. Farmers Relative to Wheat Price Received by U.S. Farmers
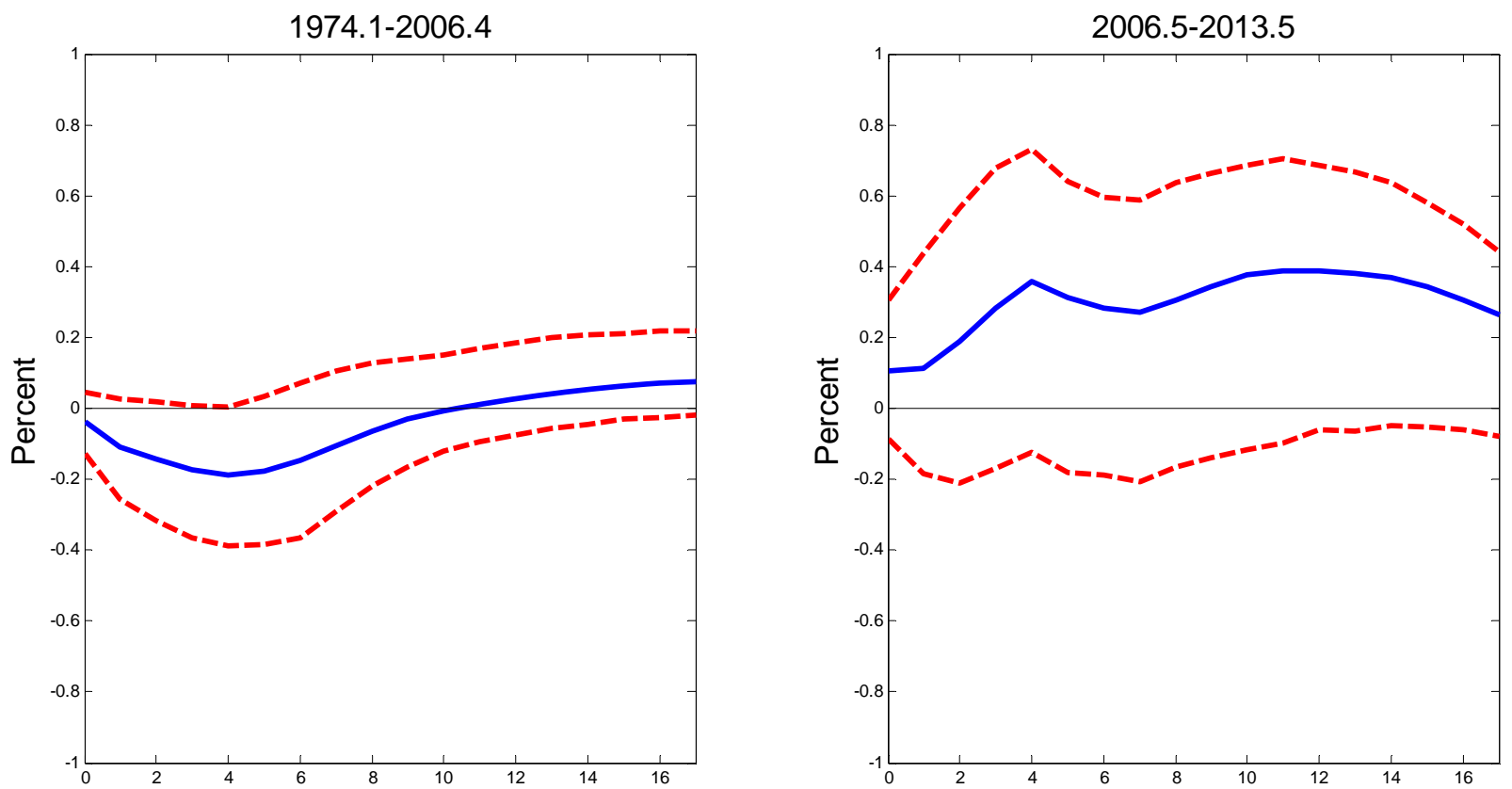

NOTES: Estimates from monthly bivariate vector autoregressions under the identifying assumption that the real price of oil is predetermined with $90 \%$ bootstrap confidence bands.

Figure 13: Response to a 1\% Real Oil Price Shock

\section{Corn Price Received by U.S. Farmers Relative to Soybean Price Received by U.S. Farmers}
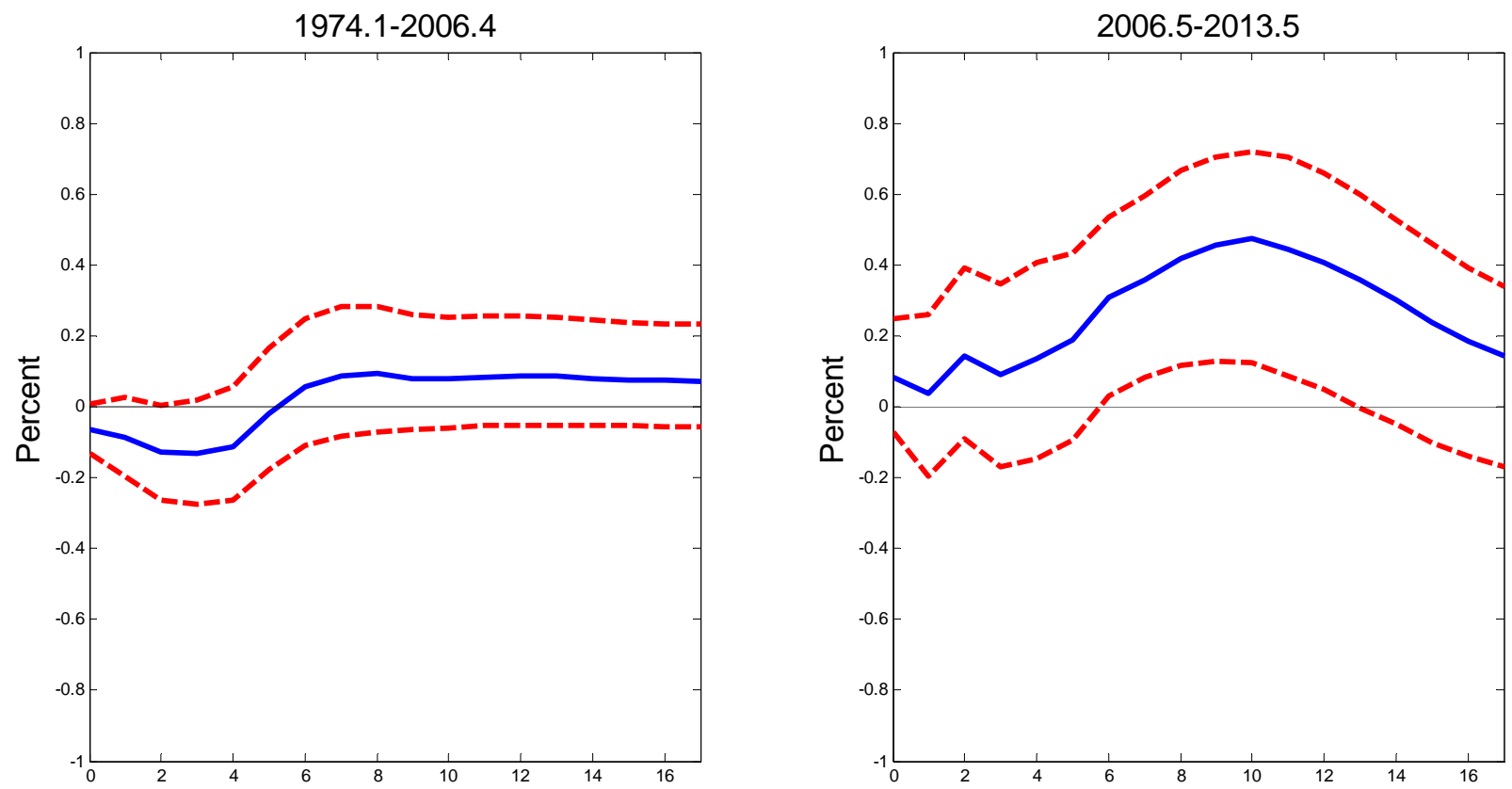

NOTES: Estimates from monthly bivariate vector autoregressions under the identifying assumption that the real price of oil is predetermined with $90 \%$ bootstrap confidence bands. 


\section{Figure 14: Response of Grain Prices to a 1\% Real Oil Price Shock}

1974.2-2006.4

Real Price of Corn
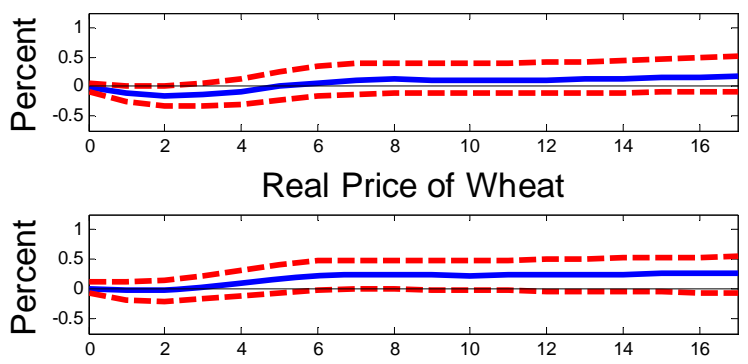

Real Price of Soybeans

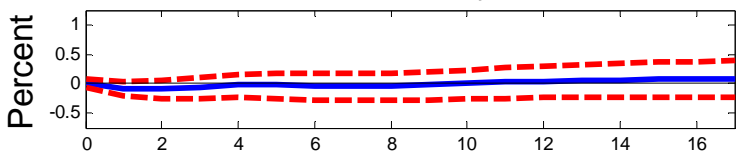

Real Price of Rice

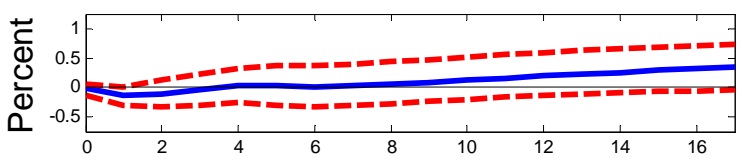

2006.5-2013.5

Real Price of Corn
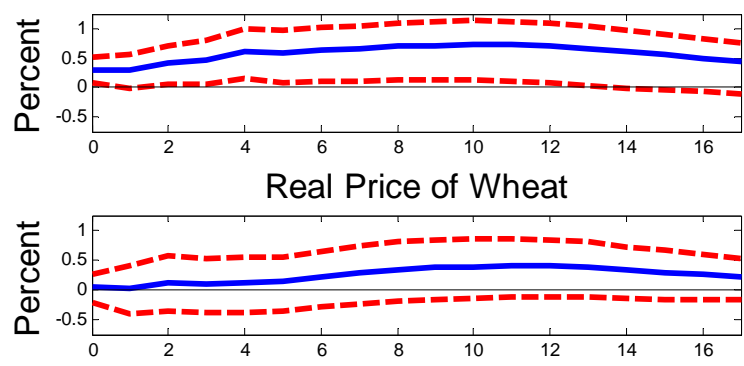

Real Price of Soybeans

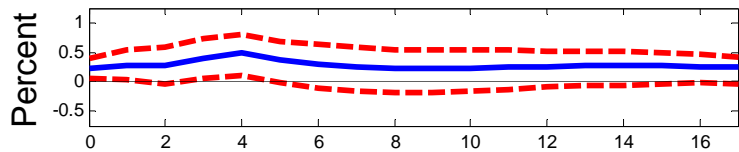

Real Price of Rice

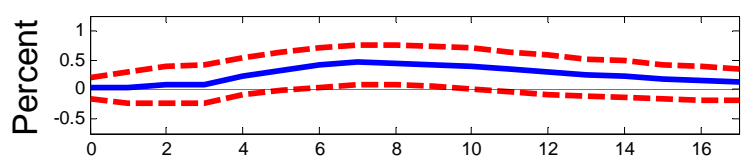

NOTES: Estimates from monthly bivariate vector autoregressions under the identifying assumption that the real price of oil is predetermined with $90 \%$ bootstrap confidence bands.

Figure 15: Response of Livestock Prices to a 1\% Real Oil Price Shock

1974.2-2006.4

Real Price of Cattle
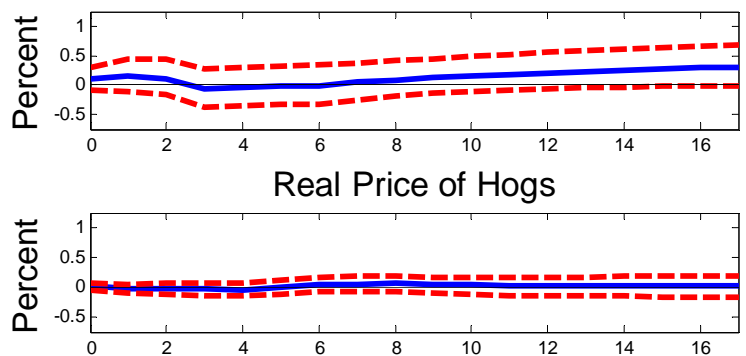

Real Price of Turkey

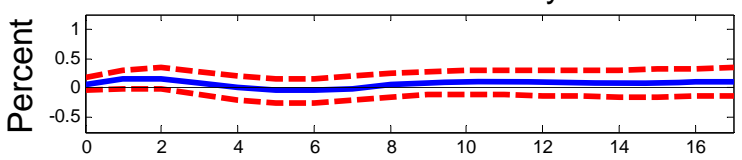

2006.5-2013.5

Real Price of Cattle
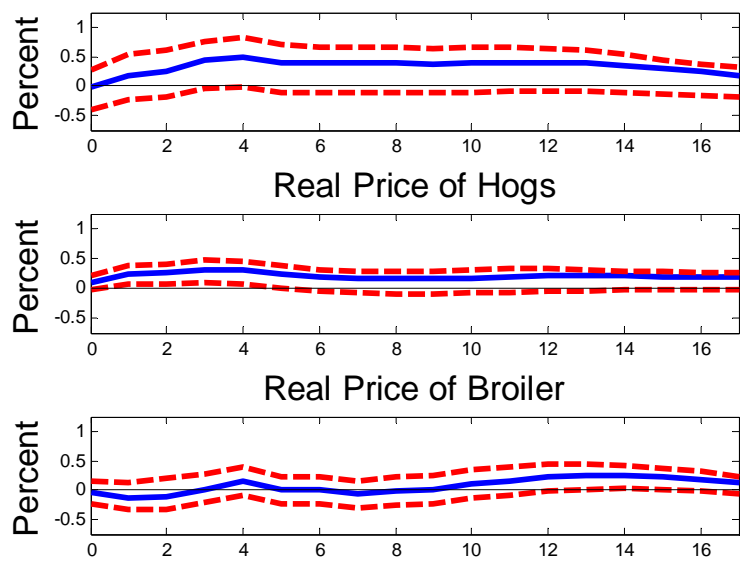

Real Price of Turkey

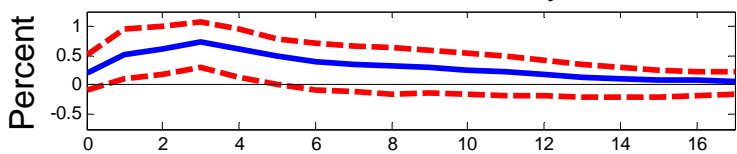

NOTES: Estimates from monthly bivariate vector autoregressions under the identifying assumption that the real price of oil is predetermined with $90 \%$ bootstrap confidence bands. 
Figure 16: Response to a 1\% Real Oil Price Shock

2006.5-2013.5
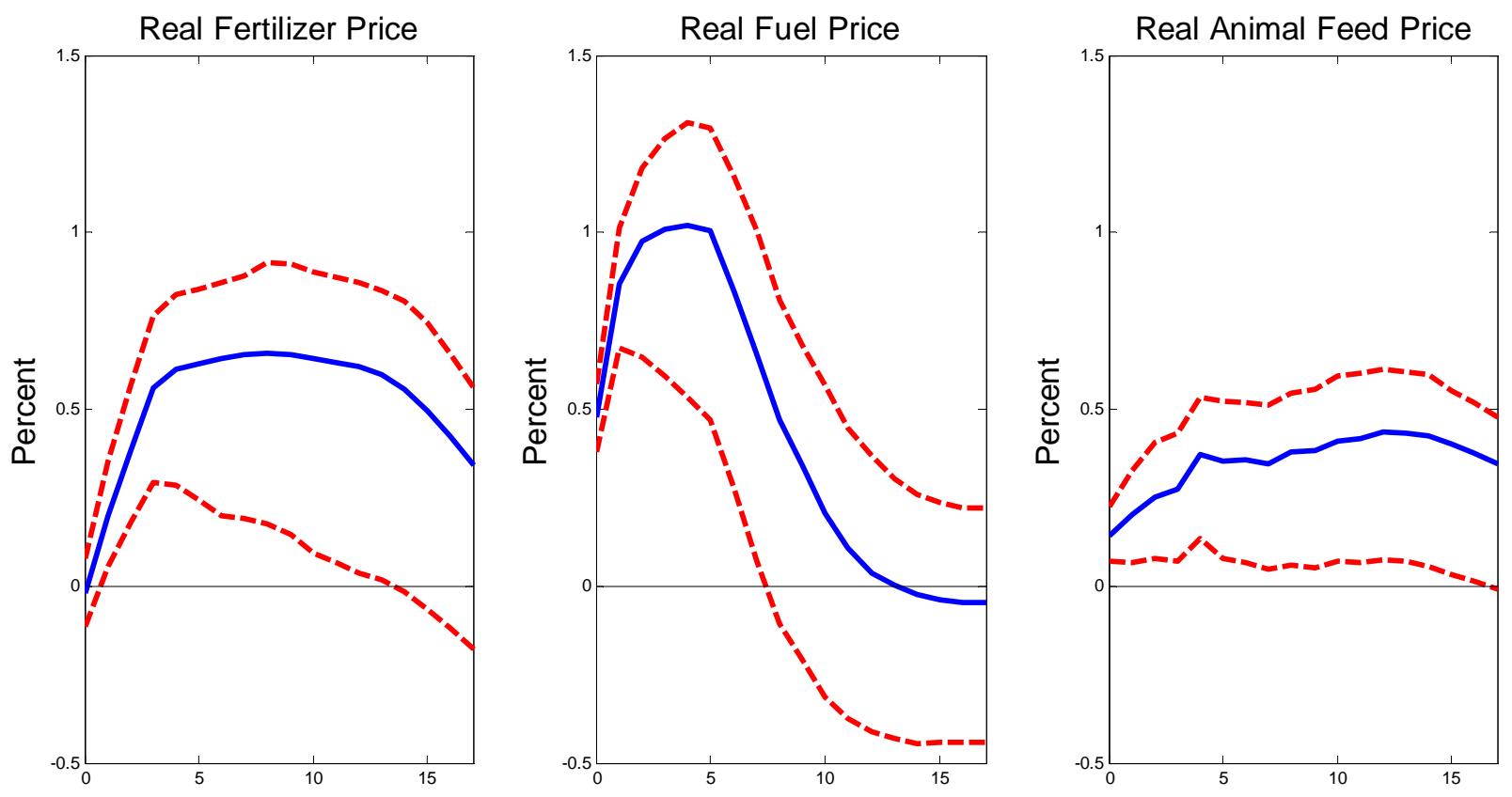

NOTES: Estimates from monthly bivariate vector autoregressions under the identifying assumption that the real price of oil is predetermined with $90 \%$ bootstrap confidence bands.

Figure 17: Spread of U.S. Diesel Price Relative to the Price of Imported Crude Oil 2006.5-2013.5

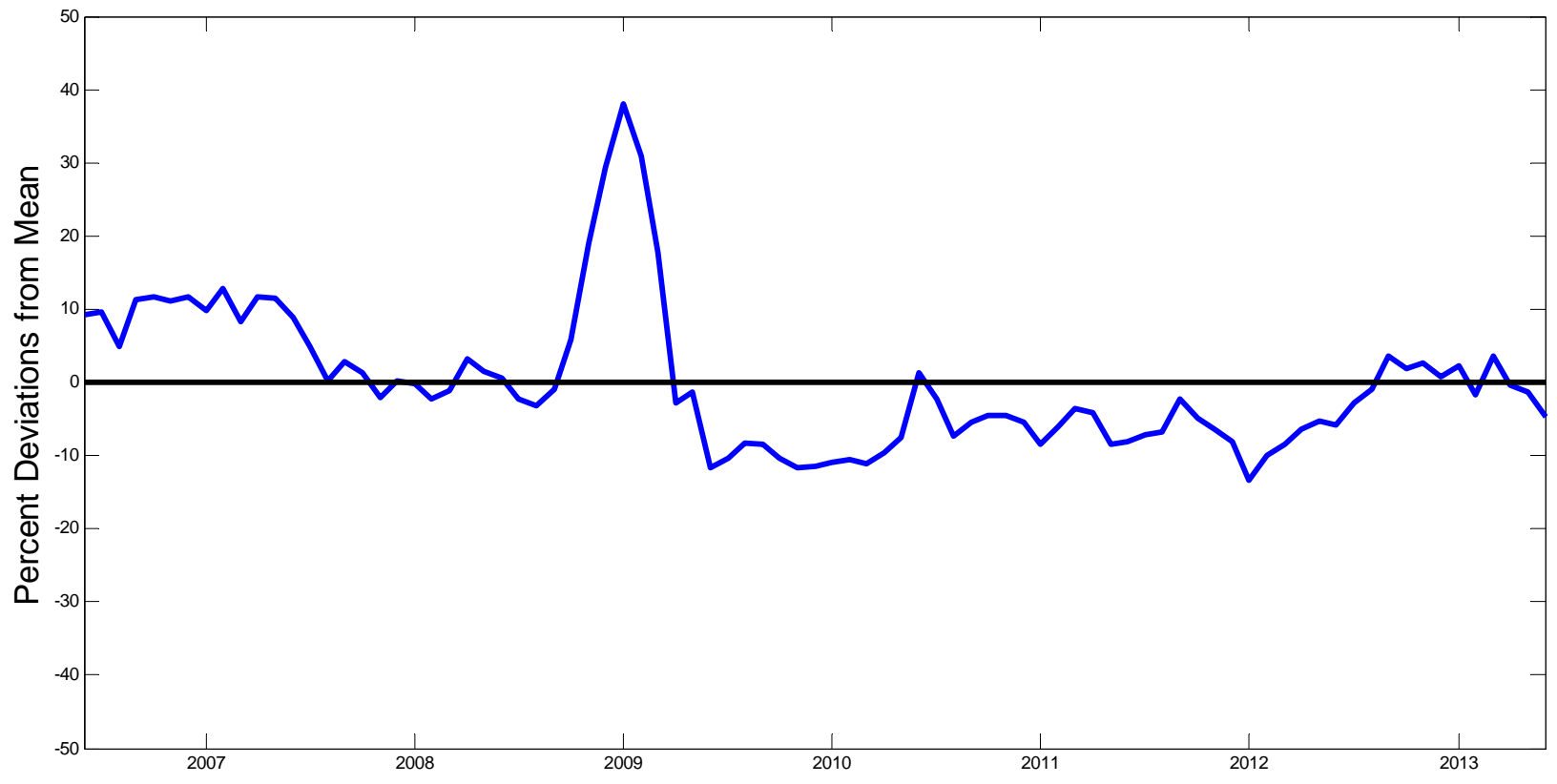

NOTES: Authors' computations based on the data described in the appendix. 
Figure 18: Response of CPI/PPI Spread to a 1\% Real Oil Price Shock by Dairy Product 2006.5-2013.5
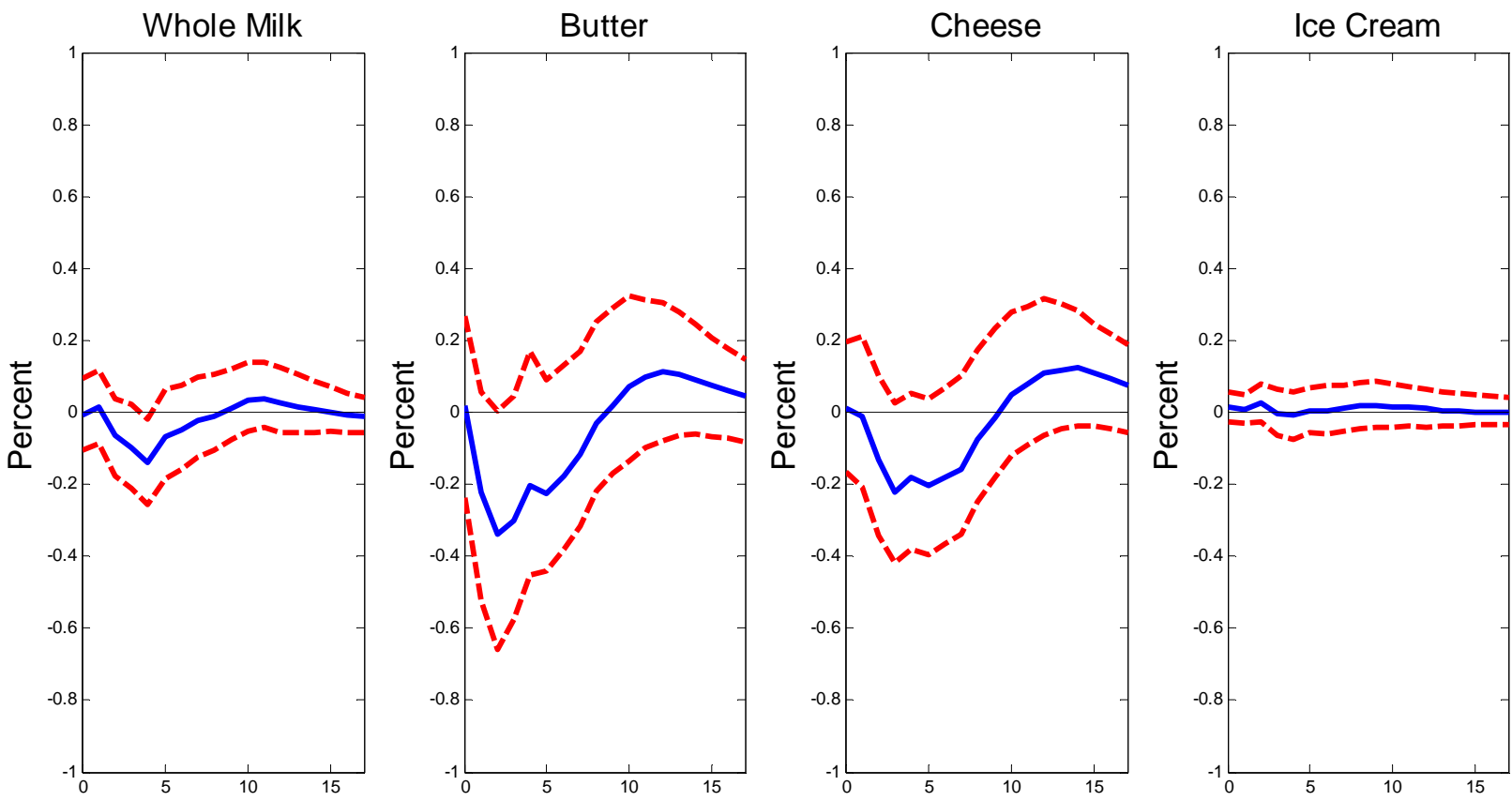

NOTES: Estimates from monthly bivariate vector autoregressions under the identifying assumption that the real price of oil is predetermined with $90 \%$ bootstrap confidence bands.

Figure 19: Response to a 1\% Real Oil Price Shock of Farm to Retail Price Spread by Dairy Product 2006.5-2013.5
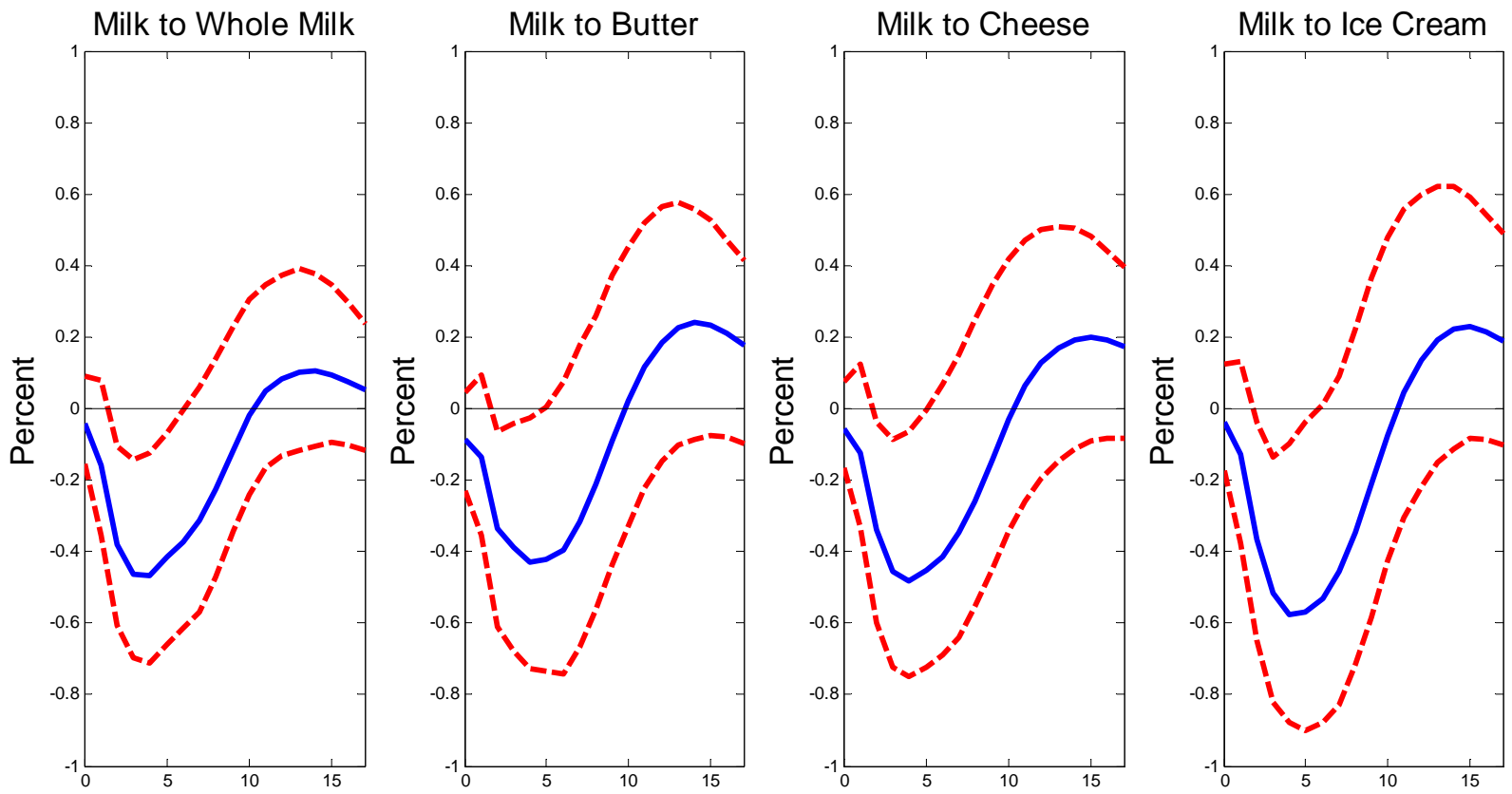

NOTES: Estimates from monthly bivariate vector autoregressions under the identifying assumption that the real price of oil is predetermined with $90 \%$ bootstrap confidence bands. 
Figure 20: Response of Pork and Beef Price Spreads to a 1\% Real Oil Price Shock 2006.5-2013.5
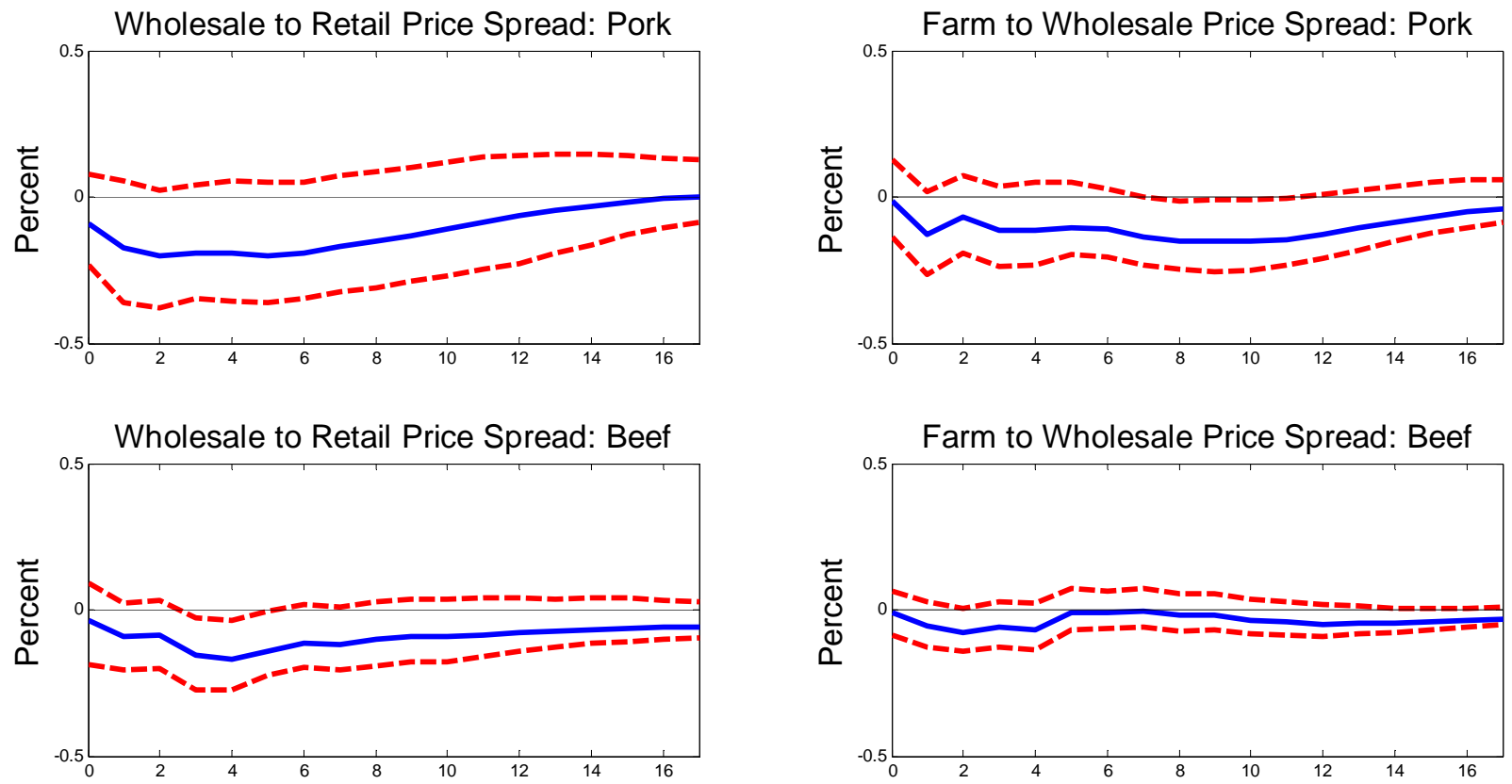

NOTES: Estimates from monthly bivariate vector autoregressions under the identifying assumption that the real price of oil is predetermined with $90 \%$ bootstrap confidence bands.

Figure 21: Response of Chicken and Turkey Price Spreads to a 1\% Real Oil Price Shock 2006.5-2013.5
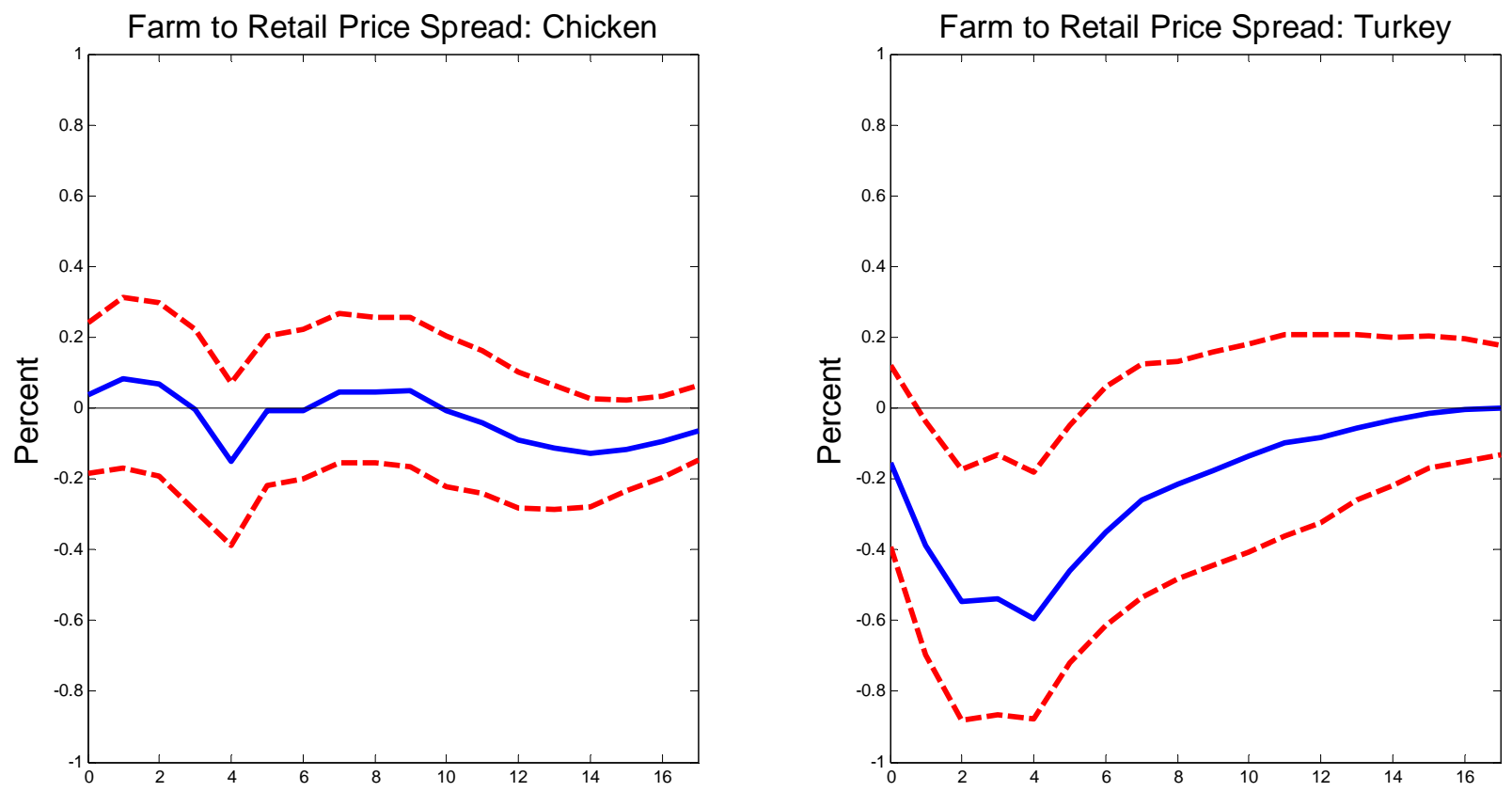

NOTES: Estimates from monthly bivariate vector autoregressions under the identifying assumption that the real price of oil is predetermined with $90 \%$ bootstrap confidence bands. 


\section{Figure 22: Response to a 1\% Real Oil Price Shock of Wheat-Related Products}

2006.5-2013.5
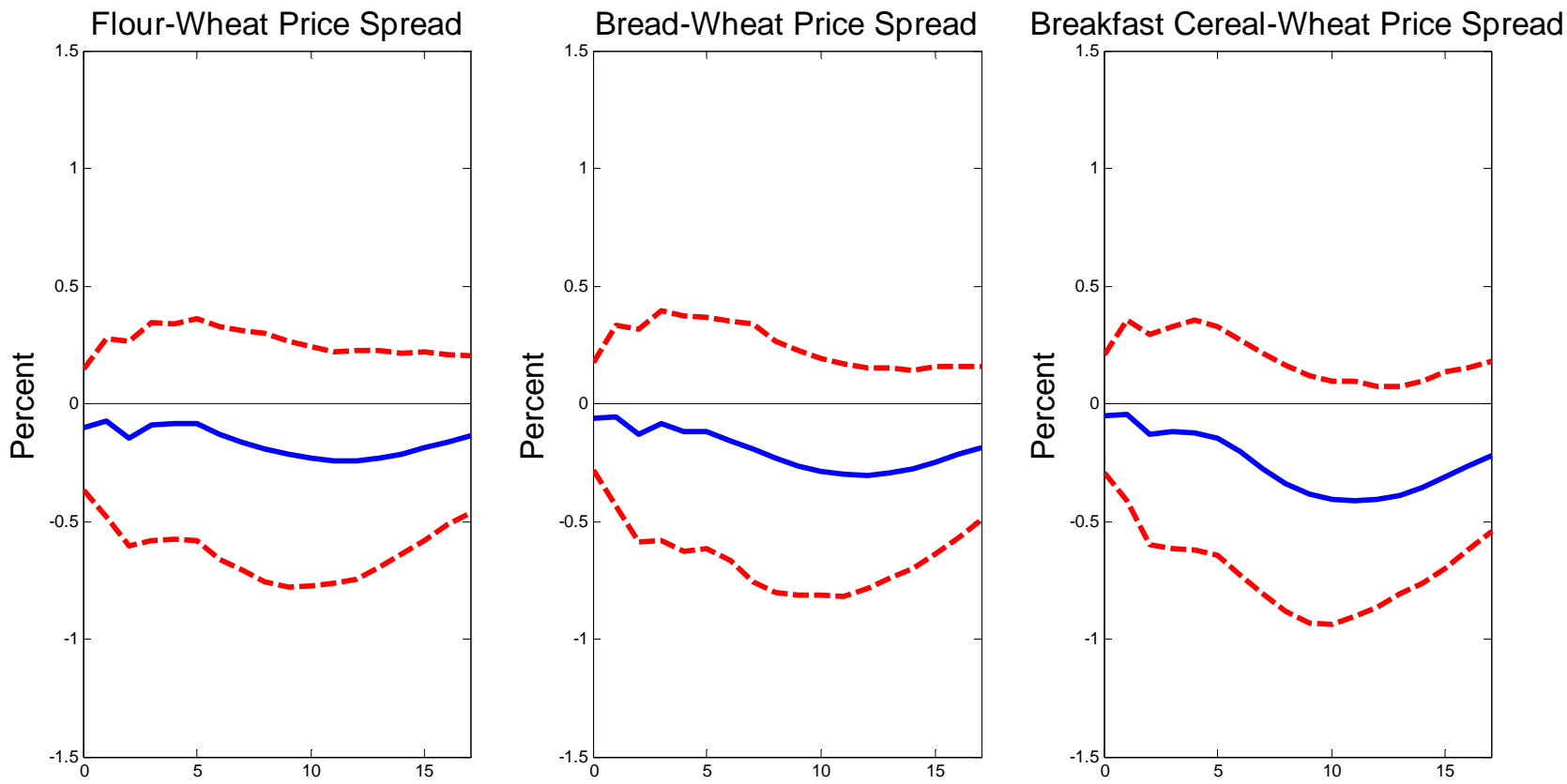

NOTES: Estimates from monthly bivariate vector autoregressions under the identifying assumption that the real price of oil is predetermined with $90 \%$ bootstrap confidence bands.

Figure 23: Response to a 1\% Real Oil Price Shock of the Cost of Eating Out Compared to at Home 2006.5-2013.5

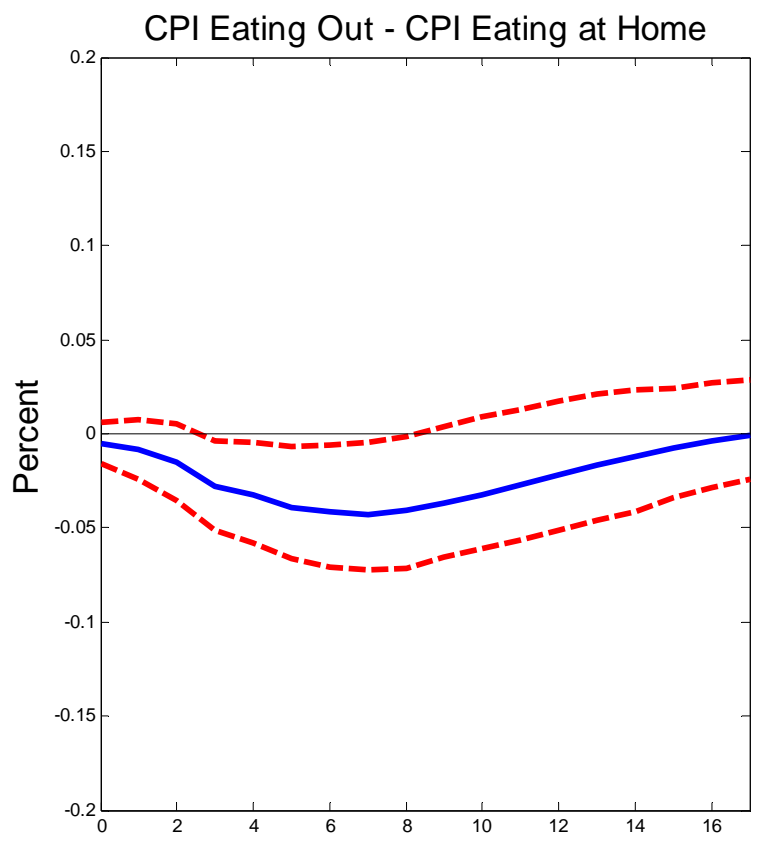

NOTES: Estimates from monthly bivariate vector autoregressions under the identifying assumption that the real price of oil is predetermined with $90 \%$ bootstrap confidence bands. 
Figure 24: Responses of Grain Prices to Global Flow Demand Shocks 2006.5-2013.5
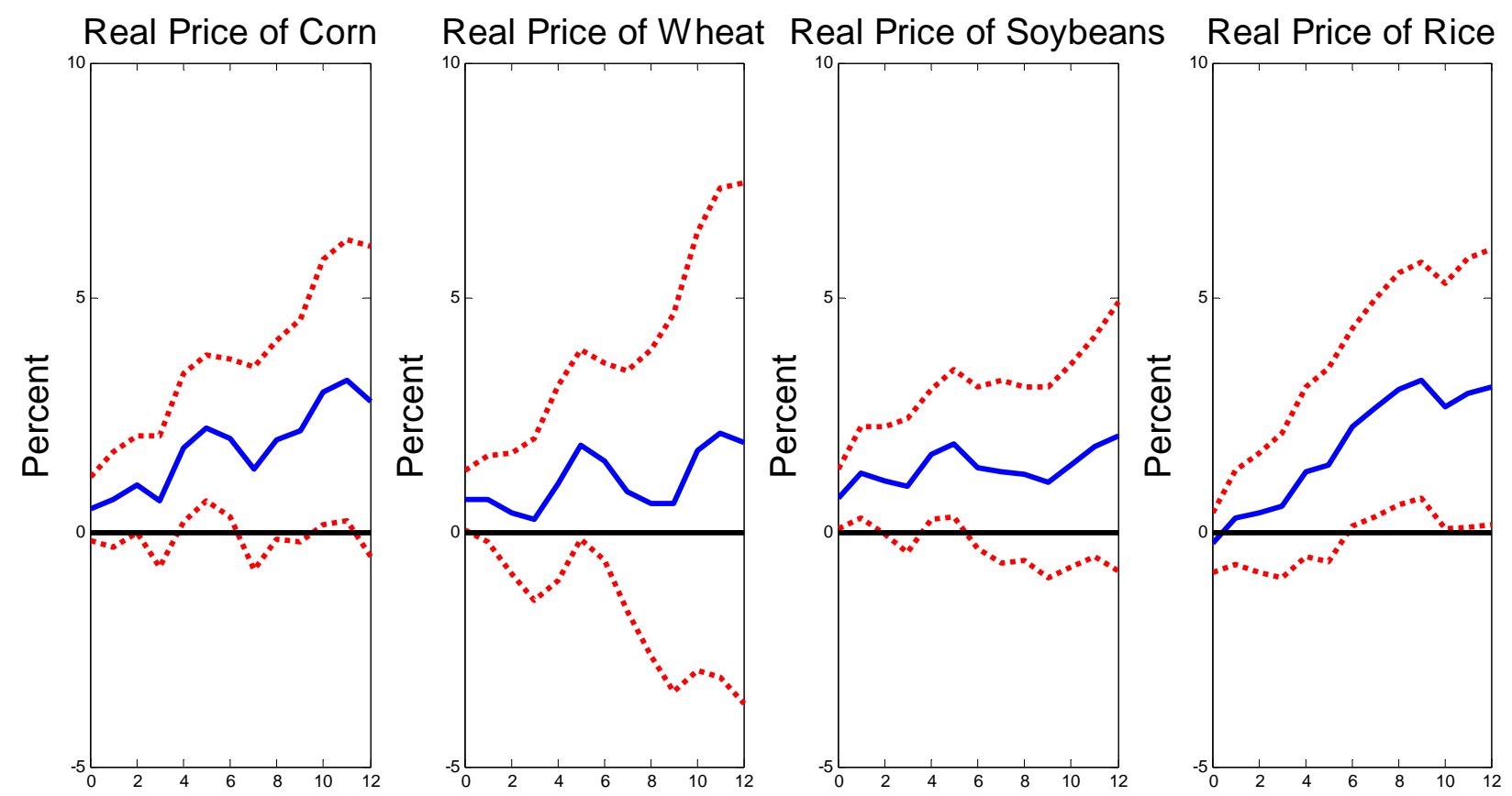

NOTES: Estimates from distributed lag models relating the growth rate in each real grain price to exogenous flow demand shocks obtained from an update of the model of Kilian and Lee (2013) with 1standard error bootstrap confidence bands.

Figure 25: Growth Rate in Grain Prices Unexplained by Flow Demand Shocks 2006.5-2013.5

Growth of Real Price of Corn Unexplained by Flow Demand Shock

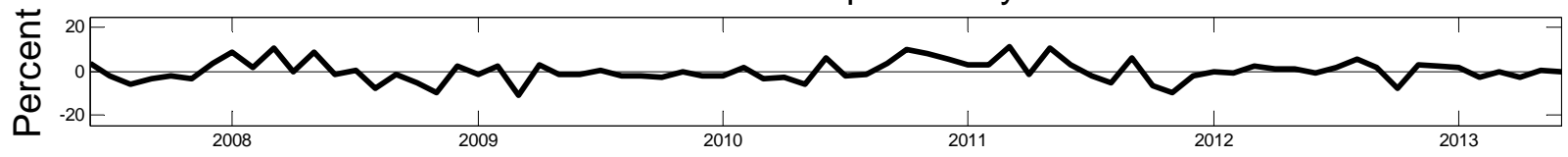

Growth of Real Price of Wheat Unexplained by Flow Demand Shock

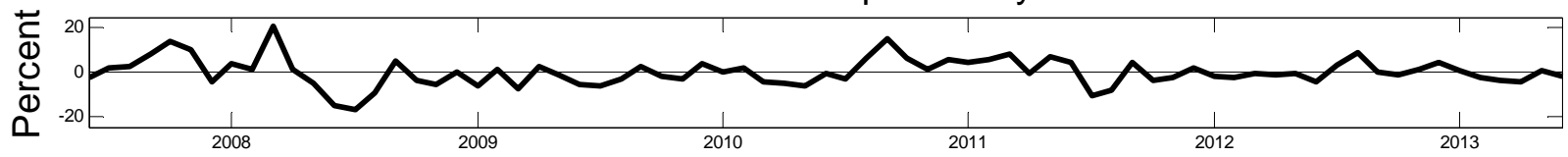

Growth of Real Price of Soybeans Unexplained by Flow Demand Shock

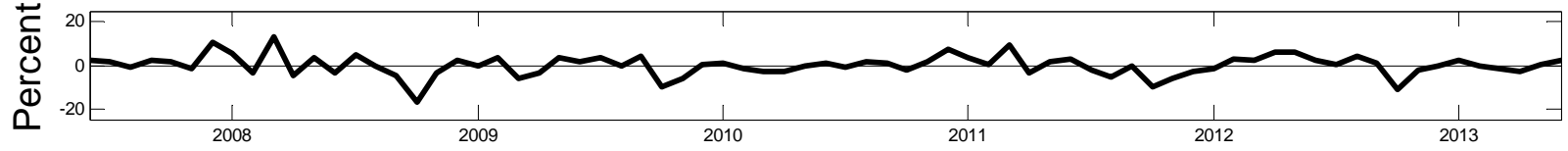

Growth of Real Price of Rice Unexplained by Flow Demand Shock

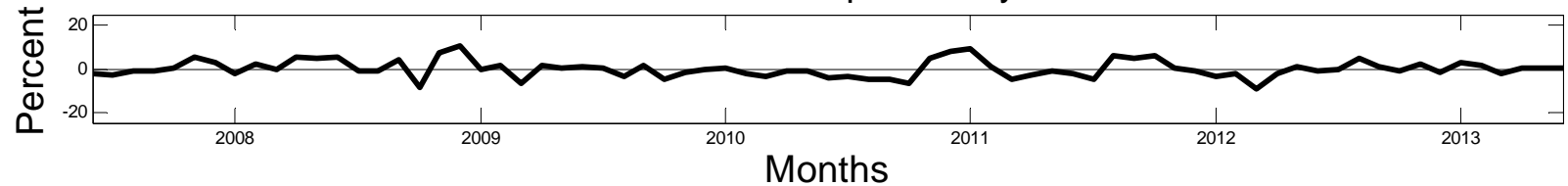

NOTES: Residuals from distributed lag models relating the growth rate in each real grain price to exogenous flow demand shocks obtained from an update of the model of Kilian and Lee (2013). 


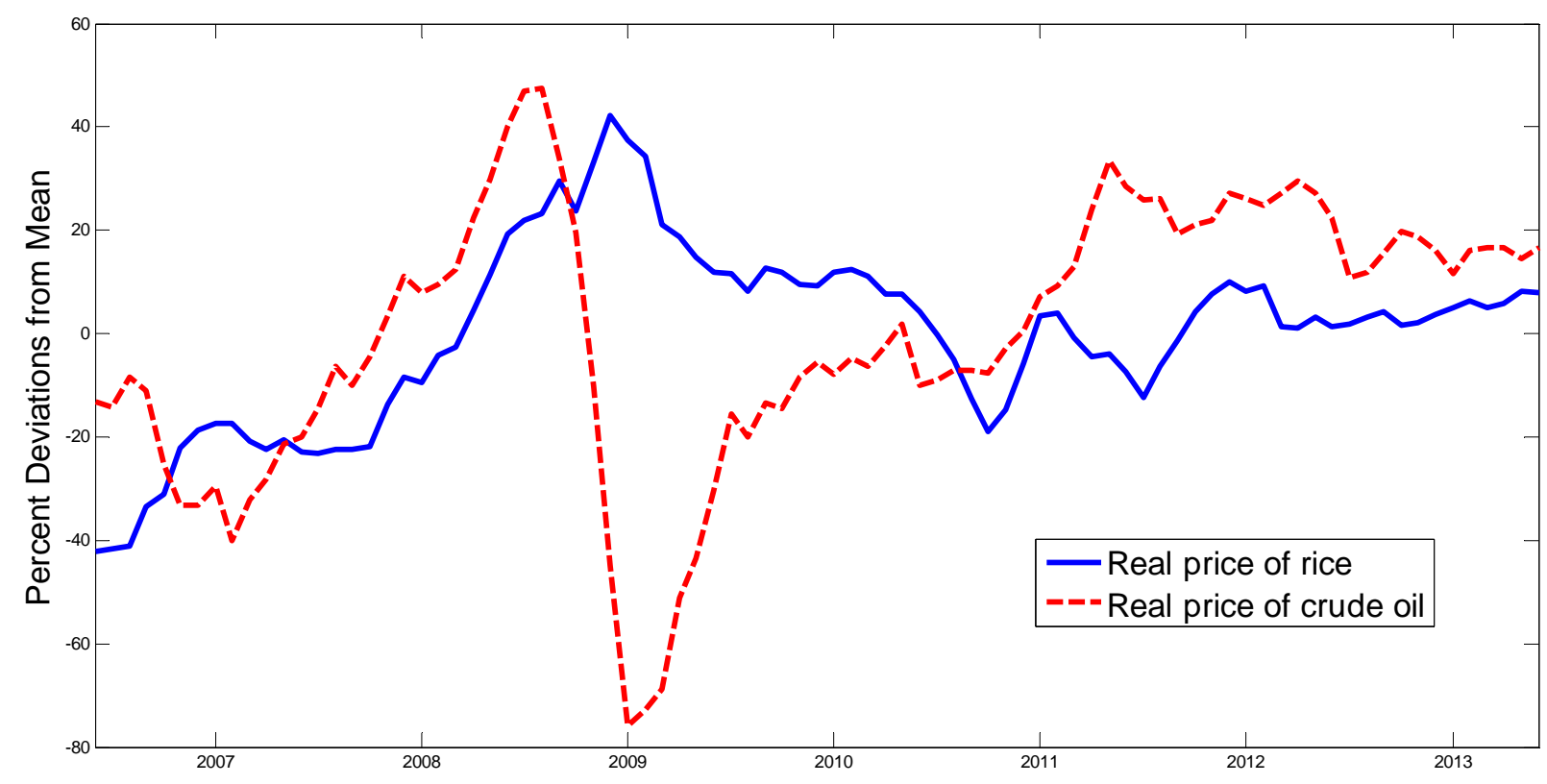

NOTES: Authors' computations based on the data described in the appendix.

\section{Data Appendix:}

The nominal price of crude oil is obtained from the Monthly Energy Review of the U.S. Energy Information Administration. We follow the literature in using the U.S. refiners' acquisition cost for crude oil imports as a proxy for the global price of oil. The same source also provides the U.S. refiners' price of No 2. diesel fuel to end users excluding taxes.

All consumer price index (CPI) and producer price index (PPI) data are obtained from the Bureau of Labor Statistics. The aggregate and disaggregate indices refer to prices paid by all urban consumers and are seasonally adjusted.

Monthly prices received by U.S. farmers for corn, wheat, soybeans, rice, cattle, hogs, live broiler and live turkey are provided by the U.S. Department of Agriculture, which also makes available indices of the cost of fuel, fertilizer and animal feed paid by U.S. farmers. Additional monthly price data for farm inputs issued at quarterly frequency were obtained from the National Agricultural Statistics Service for January 1988 to October 1995. 